NBER WORKING PAPER SERIES

\title{
MULTIFACETED AID FOR LOW-INCOME STUDENTS AND COLLEGE OUTCOMES: EVIDENCE FROM NORTH CAROLINA
}

\author{
Charles T. Clotfelter \\ Steven W. Hemelt \\ Helen F. Ladd \\ Working Paper 22217 \\ http://www.nber.org/papers/w22217 \\ NATIONAL BUREAU OF ECONOMIC RESEARCH \\ 1050 Massachusetts Avenue \\ Cambridge, MA 02138 \\ May 2016, Revised June 2017
}

The research reported here was supported by the National Center for Analysis of Longitudinal Data in Education Research (CALDER) and the Gates Foundation. We are very grateful to Shirley Ort, Associate Provost and Director of Scholarships and Student Aid, and Lynn Williford, Assistant Provost for Institutional Research and Assessment, for sharing generously of their expertise and deep institutional knowledge with the research team - and for answering many questions about data and programmatic elements of the Carolina Covenant. We benefited from the suggestions and comments of seminar participants at Stanford University, University of Michigan, the fall 2015 meetings of the Association for Public Policy Analysis and Management (APPAM) in Miami, FL, and the winter 2017 meetings of the Western Economic Association International (WEAI) in Santiago, Chile. We are grateful to Dan Cohen-Vogel and Eric Zwieg for many helpful conversations about data. We thank Yang Zhou, Cindy $\mathrm{Wu}$, and Ying Shi for excellent research assistance. The views expressed herein are those of the authors and do not necessarily reflect the views of the National Bureau of Economic Research.

NBER working papers are circulated for discussion and comment purposes. They have not been peer-reviewed or been subject to the review by the NBER Board of Directors that accompanies official NBER publications.

(C) 2016 by Charles T. Clotfelter, Steven W. Hemelt, and Helen F. Ladd. All rights reserved. Short sections of text, not to exceed two paragraphs, may be quoted without explicit permission provided that full credit, including $(\odot$ notice, is given to the source. 
Multifaceted Aid for Low-Income Students and College Outcomes: Evidence from North

Carolina

Charles T. Clotfelter, Steven W. Hemelt, and Helen F. Ladd

NBER Working Paper No. 22217

May 2016, Revised June 2017

JEL No. I22,I23

\begin{abstract}
We study the evolution of a campus-based aid program for low-income students that began with grant-heavy financial aid and later added a suite of non-financial supports. We find little to no evidence that program eligibility during the early years (2004-2006), in which students received additional institutional grant aid and few non-financial supports, improved postsecondary progress, performance, or completion. In contrast, program-eligible students in more recent cohorts (2007-2010), when the program supplemented grant-heavy aid with an array of nonfinancial supports, were more likely to meet credit accumulation benchmarks toward timely graduation and earned higher GPAs than their barely ineligible counterparts.
\end{abstract}

Charles T. Clotfelter

Sanford School of Public Policy

Duke University

Rubenstein Hall Room 178

201 Science Drive

Box 90312

Durham, NC 27708

and NBER

charles.clotfelter@duke.edu

Steven W. Hemelt

Department of Public Policy

University of North Carolina at Chapel Hill

Abernethy Hall, Campus Box 3435

Chapel Hill, NC 27599

hemelt@email.unc.edu
Helen F. Ladd

Box 90245

Duke University

201 Science Drive

Durham, NC 27708

helen.ladd@duke.edu 


\section{Introduction}

In addition to being less likely than their more affluent peers to enter college, low-income students are also less likely to graduate after they enroll. Moreover, these income-based gaps in college completion have grown larger in recent decades (Bailey \& Dynarski, 2011). This widening occurred despite attempts to improve postsecondary access and success for low-income students. The number of students receiving need-based federal Pell grants and the average, perstudent value of those awards steadily increased from the mid-1990s to 2011 (Dynarski \& ScottClayton, 2013). In addition, states have doubled expenditures on grant aid to students since 1980 (Dynarski \& Scott-Clayton, 2013), but an increasing share of that aid is not need-based. ${ }^{1}$ Recent policy discussions have centered on the genesis and evolution of income-based gaps in college enrollment and completion, as well as on ways postsecondary institutions can improve outcomes for the low-income students they enroll.

In this paper, we study a multifaceted aid program for low-income college enrollees implemented by a leading public flagship institution. In the fall of 2003, the University of North Carolina at Chapel Hill (UNC-CH) announced a new aid program for low-income students who had gained admission through the standard process. This program was intended to promote their successful progress through college and ultimate graduation. Beginning with students entering UNC-CH in the fall of 2004, this aid program, dubbed the "Carolina Covenant," would cover the financial costs of college attendance - without loans - and provide the "Covenant scholars" with additional support services, such as mentoring by faculty and peers, career advice, professional development opportunities, and social events. We examine the effects of the Carolina Covenant on various markers of college success: earned credits, grades, and graduation. Our results

\footnotetext{
${ }^{1}$ Between 2002-2003 and 2012-2013, the share of undergraduate grant aid from states that was not need based increased by 2 percentage points, from 23 to 25 percent (NASSGAP, 2014).
} 
highlight the capacity of non-financial supports to improve the postsecondary progress and performance of low-income, underrepresented students at highly competitive institutions when layered on top of need-based, grant-heavy aid. We find suggestive, though ultimately inconclusive, evidence of positive effects of Covenant eligibility on college graduation.

The next section situates our paper and its contributions within the literature that explores the effects of college costs, information, and other supports on students' postsecondary outcomes. We focus particularly on studies that examine outcomes for enrolled students. Section III discusses the components and implementation of the Carolina Covenant. Section IV describes the data and section V outlines our empirical approach. Section VI presents our main findings and section VII concludes with a discussion of policy implications.

\section{Existing Literature}

Previous research has explored the effects of need-based aid on the postsecondary attendance choices of students (e.g., Dynarski, 2003; Deming \& Dynarski, 2010), the influence of tuition costs on college enrollment (e.g., Hemelt \& Marcotte, 2011; Heller, 1996; Kane, 1995), and the effects of merit-based scholarships on postsecondary enrollment and choice (e.g., Bruce \& Carruthers, 2014; Scott-Clayton, 2011). Much less attention has been paid to the influence of such factors (and other supports) on outcomes beyond college enrollment such as short-run persistence, academic performance, and college completion. ${ }^{2}$ We summarize here first the studies that examine such effects of financial support, second those that focus on the effects of non-financial supports, and third the few that study programs combining both types of support. The fully developed Carolina Covenant program includes financial and non-financial assistance.

\footnotetext{
${ }^{2}$ For an excellent synthesis of recent research that explores ways to improve college access in the United States, see Page and Scott-Clayton (2015).
} 


\section{A. Need- and Merit-Based Aid: Effects on Post-Enrollment Outcomes}

Examining the effects of merit aid on college completion, Dynarski (2008) found that merit-aid programs in Arkansas and Georgia increased the share of young people with a college degree by 3 percentage points, with the largest effects accruing to women. She notes, however, that her reduced-form approach cannot "separately identify the effect of aid on entry and persistence conditional on entry” (p. 579). Further, she highlights the fact that her findings suggest that "scholarships alone will not keep the bulk of dropouts from leaving college" (p. 579). Even with generous merit aid, a sizeable share of entering college students fail to persist to completion. ${ }^{3}$

Scott-Clayton (2011) and Bruce and Carruthers (2014) studied the effects of merit-based, statewide aid programs in West Virginia (PROMISE) and Tennessee (HOPE), respectively, on measures of college success. In both cases, the authors exploited a set of transparent eligibility criteria based on ACT scores and GPAs to estimate scholarship effects. The West Virginia program fully covered tuition and fees for up to four years of college for first-time, full-time college attendees at public in-state institutions (or an equivalent amount at in-state privates). The Tennessee scholarship awarded up to three-fourths of the cost of tuition and fees at in-state public institutions, a quarter of the analogous cost at in-state private institutions.

Scott-Clayton (2011) focused on college enrollees and explored effects on credit accumulation and persistence, whereas Bruce and Carruthers (2014) focused on high school graduates and explored effects along the extensive margin, that is, where students enrolled. Bruce and Carruthers (2014) found no effect of reduced college costs on overall postsecondary enrollment rates, but uncovered a substitution effect of eligibility for merit aid: Students who

\footnotetext{
${ }^{3}$ Sjoquist and Winters (2012) reevaluate different samples of the 2000 Census used by Dynarski (2008) and find little overall impact of merit aid on college completion. This finding further highlights the need to explore impacts of multifaceted aid packages on postsecondary persistence and completion.
} 
barely qualified for the Tennessee HOPE scholarship were more likely to enroll in a four-year rather than two-year college, relative to their barely ineligible counterparts. Scott-Clayton (2011) found that eligibility for the West Virginia scholarship increased the share of individuals in the state with a bachelor's degree by 1.8 to 2.3 percentage points (i.e., between 8 and 10 percent). In addition, she argued that the requirements for renewing the scholarship - a minimum GPA and number of credits - drove the main effects. That is, compared to their ineligible counterparts, students eligible for the scholarship were substantially more likely to take and complete 30 or more credits during each of their first three years of college. Such effects on key intermediate outcomes kept the treatment group on track to graduate.

These studies all pertain to merit-based aid programs. Whether we should expect similar effects for need-based aid programs is unclear given that merit- and need-based programs often differ by target population, amount of aid, delivery mechanisms, and incentives. To date, with a few notable exceptions, there is little evidence on how need-based aid affects outcomes beyond the college-entry margin. Using student-level data from Ohio, Bettinger (2004) exploited discontinuities in students' Pell grant awards (based on family size and number of children attending college) to estimate effects on persistence beyond the first year of college. He found that a $\$ 1,000$ increase in a Pell award led to roughly a 4 percentage point decrease in the likelihood that a student would drop out of college (p.28). In an experimental context, GoldrickRab et al. (2012) focused on first-year Pell grant recipients at Wisconsin public colleges and found that additional need-based aid increased the likelihood students completed a full-time credit load as well as persisted to the second year of college. Castleman and Long (2013) used data on high school seniors in Florida during the 2000-2001 academic year to examine effects of additional need-based aid (above the Pell grant) on college enrollment, persistence, credit 
accumulation, and graduation. Comparing students who received some aid (i.e., a Pell grant) to those who were eligible to receive additional aid on top of Pell, they found that an additional $\$ 1,000$ of need-based aid (in 2000 dollars) increased continual enrollment through the spring semester of freshman year and bachelor's degree completion within four years by 3.3 and 3.5 percentage points, respectively (pp. 27-28).

In contrast to Scott-Clayton (2011), Castleman and Long (2013) contend that their findings are driven "much more by the reduction in cost of attendance at public, four-year institutions than by possible incentive effects" (p. 29). Of course, the populations of students eligible for the types of aid studied in these two papers differ along important dimensions, such as academic preparation and severity of financial need. ${ }^{4}$ Still, our reading of this set of evidence is that money and incentives both matter for students' progress and success in college - as does how they are combined in specific aid programs.

\section{B. Non-Pecuniary Interventions to Improve Postsecondary Persistence and Completion}

A second line of recent research has focused on non-pecuniary interventions, such as college counseling and information provision. At present, much of this work explores the ability of such interventions to influence students' choices about college-going - whether by improving student-institution matches, (Hoxby \& Turner, 2014), encouraging students to apply for needbased financial aid (Bettinger et al., 2012), providing better information about the costs and payoffs of college (Oreopoulos \& Dunn, 2012), or counseling students through the college transition process (Castleman, Page, \& Schooley, 2014; Castleman \& Page, 2015).

Two of these studies examine short-run persistence (Bettinger et al., 2012; Castleman \& Page, 2014). Castleman and Page (2014) found that students who were offered summer

\footnotetext{
${ }^{4}$ Recent evidence shows how additional financial aid affects non-traditional, older students. Barr (2014) exploits the expansion of financial aid for college via the Post-9/11 GI Bill and finds that additional aid increases the likelihood a veteran obtains a bachelor's degree within six years of enrollment by 6 percentage points (30 percent).
} 
counseling were 5 percentage points more likely to be continuously enrolled through three semesters of college. Bettinger and colleagues (2012) found that high school seniors whose parents were offered assistance with filing the Free Application for Federal Student Aid (FAFSA) were 8 percentage points more likely to have completed two years of college (during the first three years after the experiment). These findings highlight the capacity of interventions mainly targeted at improving access to college (or higher-quality postsecondary options) to encourage persistence.

Work that considers the causal effects of in-college counseling on measures of postsecondary persistence and completion is scarce. As a part of MDRC's multi-site demonstration project, “Opening Doors,” researchers found some effects of enhanced student services for low-income students at community colleges on subsequent course registrations but no effects on measures of academic achievement (Scrivener \& Weiss, 2009). Bettinger and Baker (2014) explored the persistence effects of one-on-one, proactive, in-college coaching aimed at helping students find ways to address academic and "real-life” obstacles. The authors found that coached students were more likely to persist in college during the coaching period as well as after the treatment had ended, relative to comparison students who were not coached.

\section{Mixed Aid Programs and Postsecondary Success}

A few studies provide evidence about the importance of mixed financial and nonfinancial supports. Two focus on post-enrollment college outcomes (Scrivener et al., 2015; Angrist et al., 2009) and one begins with high school seniors to explore effects on postsecondary access and persistence (Page et al., 2016). MDRC conducted a randomized evaluation of a program fielded in three community colleges of the City University of New York (CUNY) system called Accelerated Study in Associate Programs (ASAP), which included financial 
supports like tuition waivers, free metro cards, and free textbooks, along with non-financial supports such as advising, career services, and seminars. The authors found that ASAP increased persistence, credit accumulation, and graduation - with 40 percent of the treatment group earning an associate’s degree by the end of the three-year period compared to just 22 percent of the control group (Scrivener et al., 2015, p. 51).

Angrist, Lang, and Oreopoulos (2009) tested the relative efficacy of financial incentives, non-financial supports, and a mix of both financial and non-financial assistance in the context of an experiment at a large Canadian university. The programs targeted first-time freshman in the bottom three-quarters of the achievement distribution (defined by high school GPA). One group was offered an array of non-financial supports, including peer mentoring and supplemental tutoring. A second group was offered financial awards equivalent to about one year's tuition that were tied to academic performance. A third group was offered access to both the non-financial supports and the financial incentives. All treatments were only available during the first year of college. Angrist and colleagues (2009) explored the effects of these treatments on academic performance and credits earned during the first two years of college. They found that the combined treatment increased students' GPA and number of earned credits, relative to the control group, but detected little effect of either the financial or non-financial treatment in isolation. Notably, the positive effects were driven entirely by women. ${ }^{5}$ By the second year of college, women in the treatment group earned about 0.5 more credits and had GPAs that were higher than their control-group counterparts by about 0.28 points (pp. 159-160). The authors do not look at effects on college completion.

\footnotetext{
${ }^{5}$ The positive effects of the combined treatment on female students' GPAs and credit accumulation persisted into the second year of college, when the treatments were no longer in operation. Thus, this suggests that financial incentives in conjunction with non-financial supports led to lasting improvements in academic and study skills (Angrist et al., 2009, p. 160).
} 
Finally, within the U.S. context, Page, Castleman, and Sahadewo (2016) study the effects of the Dell Scholars Program which provides generous financial support and individualized, virtual advising to low-income, college-intending high school students. The authors find suggestive effects of scholarship receipt on postsecondary persistence and marked impacts on college completion (i.e., a 25 percent increase in four-year and six-year bachelor’s degree attainment rates). Eligibility for the Dell scholarship is based on financial need, evidence of overcoming adversity, and modest academic requirements. The large completion effects uncovered by Page and colleagues (2016) contrast with the modest effects found by Angrist et al. (2009) - and together these studies underscore the need for additional evidence on how mixed financial aid programs affect students of different types in different institutional settings.

\section{Contributions}

Our research explores the effects of a need-based aid program that combines financial and non-financial supports on post-enrollment college outcomes, including completion. The Carolina Covenant is targeted at high-achieving, low-income students and the manner in which it is delivered allows us to look at the effects of mixed aid awarded after admission and enrollment on measures of postsecondary success. Further, we explore these questions at a highly selective public flagship institution, a particularly important setting given the recent finding that earnings are higher for students who attend a state flagship university (Hoekstra, 2009).

Our study contributes to the literature in four ways. First, it adds to the small, developing subset of studies that explores the effects of various types of aid on outcomes beyond college enrollment, such as performance and completion. Specifically, we examine the capacity of institutional aid and programmatic support to influence the likelihood that low-income students persist and complete college. These supports are available to students throughout the entirety of 
their college careers, which differs from past work in which financial incentives or non-financial supports were available only in the first semester to year of college (e.g., Angrist et al., 2009; Bettinger \& Baker, 2014). Second, because the Carolina Covenant includes both financial and non-pecuniary elements, our findings add to the nascent literature on the effects of aid programs that mix financial support with incentives and wrap-around services for low-income students. Third, we illustrate the importance of characterizing whether and how the "treatment" received by students eligible for the aid program evolved over time. This type of exploration is valuable for any study seeking to estimate the effects of a program or policy that has been in existence for a number of years, as the treatment-control contrast can sometimes shift in meaningful ways that shape subsequent interpretation of any effects (or lack thereof). Finally, we consider and assess the relative merits and drawbacks of two plausible research methodologies for estimating causal effects of the program. This discussion highlights the importance for researchers of paying careful attention to the choice and associated tradeoffs of study design when multiple quasiexperimental approaches are possible.

\section{The Carolina Covenant}

The Carolina Covenant aid program at UNC-CH offers low-income students financial aid packages heavy on grants and work-study funds and light on loans. The program was announced in the fall of 2003, and the first cohort of awardees entered UNC-CH the following fall, making the University of North Carolina at Chapel Hill the first public institution in the country to award loan-free financial aid packages to low-income students (Fiske, 2010). Virginia and then a number of other public universities soon followed suit, with similar programs. ${ }^{6}$

\footnotetext{
${ }^{6}$ For a much more detailed exploration of the origins of the Carolina Covenant, its components, and evolution over time, see Fiske (2010).
} 


\section{A. Brief History of the Carolina Covenant}

Drawing on research that highlighted low-income families’ particular wariness of loans and general unfamiliarly with postsecondary aid systems, the designers of the Covenant specified that a) the aid packages contain no loans; and b) the eligibility criteria be simple and clear (Fiske, 2010, pp. 24-25). Though the loan-free financial aid award is the most visible part of the Covenant, the program was also designed to address other barriers to success in college faced by many high-ability students from low-income families, including "lack of informed guidance from parents unfamiliar with the ways of higher education” (Fiske, 2010, p. 18). We discuss these components of the program below.

The first cohort of Covenant scholars, those who matriculated in the fall of 2004, totaled 224 students. Over the ensuing years, this number grew, rising to 558 students in fall of 2010, the most recent cohort of scholars for whom we have data. In total, these recipients comprise about 10 percent of all undergraduates at UNC-CH and hail overwhelmingly from North Carolina.

\section{B. Eligibility and Components of the Covenant}

The Carolina Covenant is open to incoming freshman and transfer students who meet a basic set of enrollment and financial criteria. There is no separate application process for the aid program. All admitted students who applied for financial aid are screened for the Covenant. Thus, a student must first be admitted to UNC-CH and be pursuing her first undergraduate degree in a full-time capacity. Second, the student must be dependent on parents whose adjusted gross income (AGI) is no higher than $200 \%$ of the federal poverty guidelines, an amount that varies by family size. ${ }^{7}$ Third, the student's family must have limited assets and other resources

\footnotetext{
${ }^{7}$ For the first cohort of Covenant scholars (i.e., fall of 2004), the cutoff was $150 \%$ of the federal poverty line. In all subsequent years the cutoff was $200 \%$. Eligibility is determined using family income from the prior tax year: For example, for incoming freshman in the 2015-2016 academic year, UNC-CH uses 2014 income records. We are not aware of any other state programs that use the same eligibility threshold as the Covenant and that could plausibly
} 
with which to pay for college. UNC-CH requires students to complete both the Free Application for Federal Student Aid (FAFSA) and the College Board's PROFILE application to be considered for any financial aid. The university uses information collected in the PROFILE about a family's assets to ensure Covenant recipients are students from families with historically low income, as opposed to those from families that have had a bad year or two. We do not have access to the PROFILE data, but conversations with the Office of Scholarships and Student Aid revealed that these asset conditions remove from eligibility about $10 \%$ of students initially eligible for the Covenant based solely on family income data from the FAFSA. Thus, income is the primary lever by which Covenant eligibility is determined. For the 2015-2016 academic year, a student from a family of four with a 2014 income of $\$ 47,700$ or less would be eligible to receive the Carolina Covenant. ${ }^{8}$

The majority of Covenant scholars find out about their award after accepting admission but prior to enrollment. Once a student is flagged as eligible to receive the Covenant, family income and asset claims are verified by the UNC Office of Scholarships and Student Aid after admission and before the Covenant is officially awarded. In practice, this means the total number of Covenant scholars fluctuates by a few students over the first several weeks of classes each year. ${ }^{9}$ Each spring, Covenant recipients must renew their funding for the next year by submitting the required paperwork. Criteria for renewal are simple: the student must continue to meet the income requirement, be enrolled and making good progress toward a degree at UNC-CH, and be

\footnotetext{
affect the postsecondary outcomes of students entering college. The one state program with a similar cutoff is the "emergency assistance” part of North Carolina's Temporary Assistance for Needy Families (TANF) program. It provides help with housing and utility costs to eligible, low-income families. The majority of TANF services focus on the parents (i.e., short-term training and supports that will lead to employment and self-sufficiency).

${ }^{8}$ Additional information about the Carolina Covenant can be found here: http://carolinacovenant.unc.edu/faqs/.

${ }^{9}$ In ancillary analyses using data on $8^{\text {th }}$ grade students in North Carolina public schools, we explored whether the Carolina Covenant appeared to affect recruitment and enrollment patterns. We found no consistent evidence that the existence of the program meaningfully altered the likelihood of enrollment in UNC-CH for disadvantaged students. Results are available from the authors upon request.
} 
in compliance with federal financial aid standards. Covenant scholars can receive funding for up to a maximum of nine semesters (i.e., one semester beyond four years, full-time) ${ }^{10}$ We cannot observe renewal at the student level; but, aggregate data from the Office of Scholarships and Student Aid at UNC demonstrate that nearly 100 percent of eligible students who continue at UNC renew their Covenant awards. Thus, non-renewal is unlikely to be of concern.

The first and most salient component of the Carolina Covenant is the financial award. The program covers 100 percent of unmet need, that is, the difference between the financial-aid recognized costs of attending UNC-CH for an academic year and the amount the student's family is expected to contribute, through a mix of grant and work-study awards. ${ }^{11}$ In addition to this financial support, Covenant scholars are offered a number of non-financial services. In the early years of the program (2004-2006) such services were limited in scope and mainly took the shape of faculty mentors, career exploration workshops and advising, as well as some social activities such as the "etiquette dinner.” More recent cohorts of Covenant scholars (2007-2010) have been exposed to a much greater depth and breadth of non-financial supports. Peer mentoring of new scholars by older Covenant scholars was developed during the 2006-2007 academic year. Targeted summer support for academically struggling students began in the summer of 2008 (Fiske, 2010). ${ }^{12}$ Further, a range of supports intended to address the social, emotional, and

\footnotetext{
${ }^{10}$ For students entering UNC-CH in fall 2007 or later, university policy dictates that students must appeal to enroll for a $9^{\text {th }}$ semester. If a student is granted that appeal, and remains Covenant eligible, Covenant funding continues for the $9^{\text {th }}$ semester. UNC-CH's policy is described here: http://advising.unc.edu/policies-and-procedures/additionalsemester-appeal/.

${ }^{11}$ The Covenant does not replace the amount (if any) that a family is expected to contribute based on the FAFSA. While the Covenant award makes it possible for students to graduate without borrowing, some scholars elect to borrow. This can be for a number of reasons: a) some students wish to substitute a loan for the work-study component of their award; b) some borrow for study abroad or summer programs; or c) some students may cover any remaining "expected family contribution" with loans. In almost all cases, Covenant scholars who borrow originate federal (Stafford and Perkins) loans (Shirley Ort, Associate Provost, UNC-CH Office of Scholarships and Student Aid, Personal Communication, April 13, 2014).

${ }^{12}$ Covenant scholars close to losing academic eligibility and in need of summer courses to remain eligible were provided with loans to take those courses along with academic support. At the end of the summer, the loans turned
} 
cultural challenges faced by low-income, often first-generation students of adjusting to college expanded during this later period. Examples include paying for a student's orientation expenses (along with one parent), providing for "business clothing needs," navigating students to campus wellness and academic/tutoring programs, facilitating regular interaction of students with faculty and administrators over meals, providing learning disability services, supplying funding for health insurance, and offering a variety of low- or no-cost cultural and performing arts opportunities (Shirley Ort, Personal Communication, April 30, 2015). ${ }^{13}$ Finally, the fall 2007 cohort was the first exposed to the university-wide policy limiting students to eight full-time semesters in which to complete degree requirements. For these reasons, and also because, as with any large program, there were logistical and programmatic kinks during the first few years, we view scholars entering in the fall of 2007 as the earliest cohort to experience the "full-fledged"

\section{Carolina Covenant.}

\section{Data}

We use student-level administrative data from the UNC system-wide Office of Institutional Research and Assessment. These de-identified data include demographic descriptors of students, such as gender and race and ethnicity, basic information about their pre-college preparation, such as high school GPA, SAT/ACT scores, detailed information on any and all financial aid awards, and the criteria on which need-based awards primarily rest, namely family

into grants if students successfully completed the course(s). This agreement was specified in a contract (Fiske, 2010, pp. 40-41).

${ }^{13}$ Examples of supports that were expanded for later cohorts include 1) paying for a student's orientation expenses (and that of one parent); 2) providing welcome receptions and introductions to faculty/staff/peer mentors in the fall; 3) holiday and end-of-year social receptions; 4) business networking workshops; 5) providing for "business clothing needs” through UNC-CH's “Styled for Success” program; 6) providing multiple opportunities to engage with other campus organizations; 7) encouraging self-formed Covenant Scholar organizations (like the Covenant Gives Back or the Covenant pre-Health Society); 8) doing triage for campus wellness and academic tutoring/support programs; 9) providing regular opportunities to dine with fellow scholars and administrators; 10) providing learning disabilities services; 11) providing funding for medical insurance; 12) providing a rich array of low- or no-cost cultural and performing arts opportunities (Carolina Performing Arts, and Playmakers). 
income and household size. Finally, these data files contain our outcomes of interest: credit accumulation, GPA, and graduation.

We identify entering freshman cohorts of students, labeled by the fall of the academic year in which they entered UNC-CH, from 2003 through 2010. We attempted to acquire data for additional years prior to 2003, but unfortunately the UNC system did not begin to regularly retain information on income and family size from student applications for financial aid until the entering class of 2003. We then restrict our analytic sample in a number of ways. First, we remove incoming transfer students from these cohorts, allowing us to focus on initial freshman enrollees. ${ }^{14}$ Second, we drop independent students - since only dependent students are eligible to receive the Covenant. Third, among dependent students, we further restrict our sample to those who report parental income information, which is necessary to be considered for any aid award. Fourth and finally, we limit our sample to students who have non-missing values of key covariates (i.e., gender, race and ethnicity, measures of high school GPA and SAT/ACT scores). ${ }^{15}$

\section{A. Identifying Covenant-Eligible Students}

Although we observe detailed information on the sources of financial aid students receive, the files we received from UNC do not identify which specific students were Covenant recipients. Our request to merge on indicators flagging anonymized recipients was denied by the Provost's committee that handles internal data requests. Lacking that information, we were forced to predict eligibility for the aid program by combining eligibility rules with detailed,

\footnotetext{
${ }^{14}$ This restriction implies that we also drop students who enroll for the first time in UNC-CH in the summer or in the spring of an academic year. We do not observe any spring enrollees (among first-time students) during our sample's timeframe. Our results are similar if we re-include the 593 students we observe first entering UNC-CH in a summer term.

${ }^{15}$ Only 2 percent of the sample (i.e., 386 students) has missing covariate information. Results and conclusions remain unchanged if we include these students in our sample and control for missing covariate information with indicator variables.
} 
student-level data that capture the key components that determine eligibility: family size, parental income, and each year’s federal poverty line. Hence, we flag eligible students solely based on the family income cutoff, which is a function of the federal poverty line in each year.

In Table 1 we compare the number of Covenant-eligible students that we predict using this approach to actual totals reported by the UNC-CH Office of Scholarships and Student Aid. We generally come close but underestimate (overestimate) the number of true, first-year Covenant scholars in early (later) years of the program. In-state students make up more than 80 percent of all recipients and over half of Covenant scholars are first-generation college students.

\section{Empirical Approaches}

The structure of the Carolina Covenant and the data available to us make possible two estimation approaches: regression discontinuity (RD) and difference-in-differences. The approaches rest on different identifying assumptions that, in turn, rely on different comparison groups. In this section, we compare the relative merits of each approach given our primary research aims and the realities of the data we have in hand.

The RD approach exploits the income-based cutoff used to identify Covenant scholars. In this approach, the treatment group is students whose family income placed them just below the cutoff for Covenant eligibility in each year of the program's existence and the comparison group is students whose family income placed them just above that threshold. The identifying assumptions are that students cannot manipulate the assignment variable (i.e., parental income) and that students just above and below the cutoff are virtually identical in terms of both measurable characteristics such as academic preparation and financial need as well as unobservable characteristics, such as motivation. 
The difference-in-differences approach measures the effects of the Covenant program as the change in performance of eligible students over time relative to that of students not eligible for the program. The baseline for measuring these changes is the performance of students entering UNC-CH in the fall of 2003, the final year before the program was introduced. Thus, changes in the performance of ineligible students over time allow us to net out the effects of confounding factors on our outcomes of interest. The key identifying assumption is that pretreatment outcomes for the treatment and control groups follow parallel trends.

In our case, one reasonable hypothesis is that students well below the income eligibility cutoff would benefit the most from the program's array of supports. This hypothesis would point toward favoring the difference-in-differences approach since the logic of RD rests on comparisons within a relatively narrow range of family income around the cutoff. Yet, the ability to interpret estimates from the difference-in-differences setup as causal turns on the assumption of parallel trends. Unfortunately, only one year (2003) of pre-Covenant data exists. Thus, we cannot formally assess pre-trends. In addition, since our data are composed of college enrollees and our main questions center on the capacity of grant aid (in place of loans) along with nonfinancial supports to affect post-enrollment outcomes such as performance, progress, and completion, we want to compare students who are likely to be balanced in terms of their ex ante propensity to apply to UNC and receive the Covenant aid. ${ }^{16}$ Within a narrower range of family income around the eligibility cutoff, such ex ante information is likely to be similar on either side of the cutoff, especially since eligibility is largely but not entirely determined by parental

\footnotetext{
${ }^{16}$ That is, if students and families have some knowledge of the Covenant program and how eligibility works, students from families with extremely low incomes might apply to UNC-CH with a stronger expectation that they would receive the Covenant aid, if admitted. In such a case, differential information about the likelihood of grant receipt would be negatively correlated with parental income and could influence application or enrollment decisions. Such students would be included in the treatment group of a traditional difference-in-differences approach, but excluded from the treatment group under an RD approach.
} 
income. These two points suggest that we privilege the RD approach. Thus, we adopt an $\mathrm{RD}$ approach as our primary identification strategy, but supplement this strategy with difference-indifference estimates at points where the difference-in-differences approach can help us address uncertainties or drawbacks of the RD approach.

The most appealing attribute of the RD setup is that it compares treatment and control groups in the same cohort. Contrast this with the difference-in-differences approach in which treatment effects are identified off of changes in the outcome over time for the eligible group compared to the ineligible group. Comparing changes in outcomes for these two groups adjusts for pre-treatment differences between the groups. The problem is that some time-sensitive factors, such as income declines due to the Great Recession, may influence the type of student eligible for the Covenant as well as postsecondary outcomes, resulting in possible bias of the difference-in-differences results. Those factors would not, however, affect the RD estimates.

The largest drawback we face in the conduct of our RD analysis is that we cannot observe whether students ultimately received the Covenant scholarship. Since Covenant eligibility is largely but not entirely a function of a student's family income, this means our indicator for Covenant eligibility incorrectly labels some ineligible students as eligible. The resulting error is likely to depress our estimates, but the small portion of misclassified students means that the downward bias is likely to be small. Thus, our $\mathrm{RD}$ approach is best thought of as a reduced-form fuzzy RD model.

We employ parametric and nonparametric approaches to RD estimation, but mainly present results from parametric models of the following basic form: 


$$
Y_{i t}=\alpha+\beta_{1} C C_{i t}+f\left(I n c_{i t}\right)+\beta_{x} X_{i t}+\delta_{t}+\varepsilon_{i t}
$$

Here, $C C_{i t}$ is an indicator equal to one if student $i$ in year $t$ was eligible to receive the Carolina Covenant. The function $f\left(I n c_{i t}\right)$ represents the relationship between the running variable (i.e., the difference between the relevant poverty threshold in a given year and a student's family income) ${ }^{17}$ and the outcome. We interact polynomial functions of this running variable with the eligibility indicator to allow the relationship between family income and the outcome to differ on either side of the cutoff. In some specifications, we insert a vector of student-level controls $\left(X_{i t}\right)$ that includes gender, race and ethnicity, household size, high school GPA, and SAT composite score ${ }^{18}$ along with year fixed effects ( $\delta_{t}$ ); finally, $\varepsilon_{i t}$ is a stochastic error term. Within this parametric setup, $\beta_{1}$ represents the effect of being eligible to receive the Carolina Covenant on the outcome of interest. ${ }^{19}$ The analytic sample for the RD results includes students in the cohorts of 2004 through 2010.

Difference-in-difference results come from models of the following basic form:

$$
Y_{i t}=\alpha+\beta_{1} C C_{i t}+\beta_{2}\left[C C_{i t} * A f t e r_{i t}\right]+\beta_{x} X_{i t}+\delta_{t}+\varepsilon_{i t}
$$

Here, $Y_{i t}$ is the outcome of interest (e.g., graduate from college in four years) for student $i$ in year $t$; $C C_{i t}$ indicates whether student $i$ in year $t$ was eligible to receive the Carolina Covenant; After $r_{i t}$ takes on the value of one for all students entering UNC-CH in the fall of 2004 and later, that is, after the Covenant program had begun. The coefficient, $\beta_{2}$, on the interaction of After ${ }_{i t}$ and $C C_{i t}$ is the coefficient of interest and represents our estimate of how eligibility for the Carolina

\footnotetext{
${ }^{17}$ The poverty line is household-size specific. We express income in 2010 dollars and re-center the eligibility cutoff on zero.

${ }^{18}$ For students who only have an ACT score, we convert their ACT score to an equivalent SAT score using the concordance table provided by the College Board (2009).

${ }^{19}$ This effect is a local average treatment effect, most applicable to observations near the cutoff.
} 
Covenant affects the particular outcome of interest. The vector $X_{i t}$ refers to student-level characteristics including gender, race and ethnicity, high school GPA, SAT composite score, real family income and its square, and household size; $\delta_{t}$ represents year effects, which set up the difference-in-differences framework and capture secular changes over time in the outcomes of interest, and $\varepsilon_{i t}$ is a stochastic error term. The estimation sample for the difference-indifferences results includes students in the cohorts of 2003 through 2010.

\section{Findings}

In the subsections that follow, we discuss our core results concerning the effects of Covenant-eligibility on measures of postsecondary progress, performance, and completion. Throughout our analyses, we pay particular attention to the treatment elements and associated effects for two groups of cohorts: the early (2004-2006) and late (2007-2010) sets of Covenant scholars. The Carolina Covenant is an evolving program. As we described earlier, in its inaugural years, the focus was more squarely on relieving the financial burden of college. In more recent years the program has expanded to include an appreciable array of non-financial supports. ${ }^{20}$

\section{A. Descriptive Statistics: Who are Covenant Scholars?}

In Table 2 we present basic descriptive statistics for the full sample and sub-samples of Covenant-eligible and Covenant-ineligible students. The full sample is 62 percent female, 67 percent white, relatively high achieving (with an average SAT score of about 1290), and consists of many well-off families (with average real parental income of nearly $\$ 107,000$ ). Relative to the whole sample, Covenant-eligible students are more likely to be minority and are slightly lowerachieving (with an average SAT score of about 1240), and they come from families with

${ }^{20}$ Conversations with the Associate Provost and Director of the Office of Scholarship and Financial Aid confirm this distinction (Shirley Ort, Personal Communication, April 30, 2015). 
markedly lower parental income. The typical Covenant-eligible student comes from a family with parental income of a bit more than $\$ 26,000$ (measured in constant 2010 dollars), which is far below the average parental income of the typical student not eligible for the Covenant - of roughly $\$ 121,000$.

\section{B. Exploration of RD Assumptions}

The ability to interpret our findings as causal effects of Covenant eligibility turns on a few key assumptions embedded in our $\mathrm{RD}$ setup. We probe these assumptions before discussing our main results. The first assumption is that students/families are unable to strategically manipulate the assignment variable. Since Covenant receipt is a function of parental income and family assets reported via the FAFSA and College Board PROFILE, respectively, and verified after admission by the UNC-CH Office of Scholarships and Student Aid prior to award disbursement, there is limited scope to game eligibility. In Figure 1, we present the distribution of our running variable (i.e., parental income minus cutoff) and test for any jump at the threshold using the McCrary (2008) test - for all cohorts and separately for the early (2004-2006) and late (2007-2010) groups of cohorts. In no case do we detect statistically significant evidence of bunching near the threshold suggestive of running variable manipulation. ${ }^{21}$

The second key assumption is that in the neighborhood of the cutoff, we can consider students on either side as equivalent in all observed and unobserved respects except one: eligibility for the Carolina Covenant. Thus, we should see few differences in observable, precollege characteristics of eligible and ineligible students as we move across the threshold for

\footnotetext{
${ }^{21}$ Though statistically insignificant, the density plot for the cohorts of 2007 to 2010 suggests that there may be a small discontinuity that we are unable to detect. Encouragingly, we find no discontinuities in observable covariates at the eligibility cutoff for those later cohorts. As an extra step to ensure that any small heaping has no influence on our main findings, we do two things. First, we adopt a type of "donut RD” approach (Barreca et al., 2011) and reestimate our main models dropping observations at heaping points. Second, we drop the cohort of 2010, which appears to drive a good portion of any small density discontinuity, and re-estimate our main RD models. In both cases, our central findings and conclusions hold. Results from these supplementary approaches are available from the authors upon request.
} 
eligibility. Figure 2 shows scatterplots of select baseline characteristics by the running variable, where the cutoff is re-centered on zero. For each baseline characteristic, we present separate graphs for the early (2004-2006) and late (2007-2010) sets of cohorts. To highlight changes around the cutoff, we limit the figures to students from families with income that falls within +/200 percent of the federal poverty threshold. This roughly translates to a range of $\$ 0$ to $\$ 83,000$ (measured in 2010 dollars). ${ }^{22}$ The solid lines to each side of the cutoff are the estimated regression lines from a simple parametric specification based on a data window of $+/-75,{ }^{23}$ which corresponds to a parental income range of $\$ 24,000$ to $\$ 56,000$.

For the late cohorts of 2007 to 2010, we see no evidence of imbalance in terms of precollege achievement or demographics. The early cohorts, in contrast, exhibit some evidence of imbalance at the eligibility threshold, especially in terms of measures of pre-college academic performance. In Appendix Table A1, we present a range of parametric and nonparametric estimates of how a number of student-level covariates move as we pass through the cutoff, separately for the early (2004-2006) and late (2007-2010) groups of scholars. In addition, we show analogous estimates for the one pre-policy cohort of 2003. Once again, across a range of data windows and specifications, results for the late cohorts raise no concerns. For the early cohorts of 2004 to 2006, it appears that Covenant-eligible students were somewhat lower performing coming into college compared to their barely ineligible counterparts. ${ }^{24}$ Given these

\footnotetext{
${ }^{22}$ In terms of the full analytic sample of UNC-CH students, a family income of $\$ 83,000$ would place a student at roughly the $44^{\text {th }}$ percentile in the distribution of real parental income.

${ }^{23}$ For these simple parametric models, we limit the sample to $+/-75$ from the cutoff and include a linear term in the running variable which is allowed to differ on either side of the cutoff. The nonparametric bandwidth selector developed by Calonico, Cattaneo, and Titiunik $(2014,2015)$ suggested optimal bandwidths ranging from $+/-48$ to $+/-100$ for the vast majority of outcomes in our paper; thus, we adopt an intermediate value for the data window on which we estimate our local linear regressions, $+/-75$. Estimates are similar and conclusions unchanged if we instead use a data window of $+/-50$ or $+/-100$.

${ }^{24}$ Left addressed, this imbalance would negatively bias our results. Such a difference runs contrary to the story that higher-achieving students who barely miss the Covenant threshold go elsewhere to college in search of better aid
} 
observed differences, we do two things: First, we control for a range of student-level

characteristics in our preferred RD specification. Second, since one might worry that the

covariates we employ fail to capture some remaining unobserved differences between the two

groups of students to either side of the cutoff, we exploit the fact that the 2003 pre-cohort

demonstrates a similar imbalance in pre-college achievement (Appendix Figure A1). Thus, for

the early cohorts, we can use this pre-cohort within a difference-in-differences setup to net out

any remaining, unobserved differences between the groups. If our difference-in-difference and

$\mathrm{RD}$ estimates are similar, we have additional assurance that the inclusion of our student-level

covariates in the RD setup is sufficient for arriving at causal estimates of the effects of the

Covenant for the early cohorts. ${ }^{25}$

\section{Unpacking the Implicit Financial Treatment}

Before turning to effects of the aid program, we use the rich measures of financial aid at our disposal to characterize the financial treatment experienced by the typical Covenant-eligible student at the threshold. We pay particular attention to how the treatment-control contrast encountered by students in the earlier cohorts differs, if at all, from the contrast experienced by those in the latter group of scholars.

For the purposes of this exercise, we group aid into four main categories: loans (which include federal, state, local, and institutional loans); institutional, need-based grant aid; work study aid; and Pell grant aid. Total aid is thus the sum of these four categories. ${ }^{26}$ Figure 3

packages. Indeed, this would create a discontinuity in the opposite direction of what we observe, leaving relatively higher-achieving students below the threshold.

${ }^{25}$ We primarily rely on the RD estimates for the later cohorts given our inability to use more than one pre-policy cohort to establish pre-trends and the concern that time-varying shocks correlated with Covenant eligibility and our postsecondary outcomes of interest could pollute estimated effects from a difference-in-differences setup.

${ }^{26}$ Students may receive special scholarships or other types of aid that fall outside these categories. In our sample, such aid is relatively small in magnitude. Further, there is no difference at the eligibility threshold in the likelihood or amount of such "other aid." Thus, we abstract from its inclusion to focus on substantive differences in the core financial components of students' first-year aid packages at the cutoff for Covenant eligibility. 
presents RD figures by cohort group for amounts of total aid, loans, and institutional grants.

Table 3 shows corresponding point estimates from simple, local linear regressions within +/- 75 of the cutoff, represented by the solid lines in Figure 3, for these as well as additional financial outcomes.

The graphs in Figure 3 and point estimates from Table 3 tell a similar story about the evolution of the treatment-control contrast. Covenant-eligible students in the early iterations of the program (2004-2006) received more total aid than their barely ineligible counterparts. That additional aid totaled roughly $\$ 1,300$ and was comprised almost entirely of institutional grant dollars. For the early cohorts of 2004 to 2006, we find no statistically significant effect of Covenant eligibility on the likelihood of having loans in one’s first-year financial aid package. ${ }^{27}$ But, for the late cohorts of 2007 to 2010, we find that a Covenant-eligible student is about 16 percentage points less likely to have loans in her first-year financial aid package, relative to her barely ineligible counterpart (Panel A, Table 3). ${ }^{28}$ Interestingly, in these latter cohorts, Covenanteligible and Covenant-ineligible students near the threshold received roughly comparable amounts of total aid. Thus, the financial treatment for the cohorts of 2007 to 2010 should be thought of as a substitution of roughly $\$ 1,000$ of loans for $\$ 1,000$ of grants, with a dollop of a few hundred additional dollars of grant aid on top of that swap and access to a variety of nonfinancial supports. The treatment at the threshold for the early cohorts of scholars (2004-2006) was an increase in the first-year aid package of about \$1,300 in grant aid alongside limited nonfinancial supports. In both cases, Covenant-eligible students received more institutional, need-

\footnotetext{
${ }^{27}$ This estimate and interpretation are local to the eligibility cutoff. As one moves outward in both directions from the cutoff, the difference in the probability of having loans as a part of the first-year financial aid package grows, with students well below the eligibility cutoff much less likely to have a loan as a part of their aid package than students a bit farther above the Covenant cutoff.

${ }^{28}$ We explored whether Covenant eligibility influenced the type of loan taken out by a student. Specifically, anecdotal evidence suggested that Covenant scholars may have been more likely to originate Stafford or Perkins loans. We find no effect of Covenant eligibility on the likelihood a student has a Stafford or Perkins loan in her firstyear financial aid package.
} 
based grant aid (of a bit over $\$ 1,000$ ) in their first-year aid packages than their barely ineligible counterparts.

\section{Effects on College Completion}

We now turn to the effects of Covenant eligibility on college graduation. We focus on timely college completion, that is, within four years of initial enrollment in UNC-CH. ${ }^{29}$ Figure 4 presents RD graphs by cohort group. Table 4 shows a range of parametric and nonparametric $\mathrm{RD}$ estimates of the effect of Covenant eligibility on four-year graduation rates in the first five columns. ${ }^{30}$ In columns 6 and 7 we present estimates from our difference-in-differences approach. Recall that our primary interest in doing so is to compare results from our preferred parametric RD specification for the early cohorts of 2004 to 2006, which includes student-level controls and is estimated within a narrow window around the cutoff (column 4), with the difference-indifference results for that same set of cohorts.

Note first the stability of the magnitude of the point estimates for the late cohorts of 2007 to 2010 as we move from a wider window of data with controls (column 2) to a narrower window of data without controls (column 3). Further, within the narrowest window of data on which we estimate our parametric models, the point estimate barely budges when we add our

\footnotetext{
${ }^{29}$ We focus on four-year completion rates for two reasons. First, we can observe this time horizon for all of our cohorts. Second, RD estimates of effects of Covenant eligibility on six-year graduation rates for the early cohorts of 2004 to 2006 and the subset of more recent cohorts for which we can calculate six-year completion rates (2007 and 2008) are extremely similar to estimates of effects on four-year completion rates. For example, the coefficients and standard errors from our preferred RD specification (column 4 in Table 4) when completing college in six years is the outcome are $0.012(0.045)$ for the 2004-2006 cohorts and 0.055(0.050) for the 2007-2008 cohorts. These estimates are very similar to their counterparts in Table 4. Thus, there is little support for the notion that Covenant eligibility hastens college completion without increasing overall attainment rates.

30 Our nonparametric estimates employ rectangular (i.e., uniform) kernels. We also conducted our nonparametric analyses with triangular kernels, which weight observations close to the cutoff more than those farther from the cutoff. Results are extremely similar and we prefer the use of rectangular kernel on the grounds articulated by Lee and Lemieux (2008) - namely that a more transparent way to increase the weight of observations close to the cutoff is to estimate local linear regressions within increasingly smaller bandwidths. Thus, when using a rectangular kernel, one can more easily compare estimates from columns 3 and 5 in Table 4, which both amount to estimating local linear regressions within a window of data; in the case of column 5, that "window" is a data-driven, "optimal" bandwidth selected by the procedures outlined in Calonico, Cattaneo, and Titiunik $(2014,2015)$.
} 
vector of student-level controls (moving from column 3 to 4). Contrast this stability with the pattern of point estimates of effects for the early cohorts of 2004 to 2006. Consistent with the imbalance of student characteristics at the cutoff shown earlier, we find that the inclusion of covariates matters for the direction and magnitude of this point estimate. Indeed, the nonparametric estimate at the cutoff is negative. Encouragingly, for these early cohorts, our preferred RD estimate in column 4 is very similar to an estimate from the difference-indifferences approach in column 7. Both are about 0.02 and statistically insignificant. Taken together, the RD and difference-in-differences estimates (along with the ocular evidence) suggest that there is no effect of Covenant eligibility in the early cohorts of 2004 to 2006 on the likelihood of graduating from college in four years. ${ }^{31}$

We find suggestive, though not conclusive, evidence that Covenant eligibility in the later cohorts of 2007 to 2010 increased the likelihood of graduating from college in four years. Though our RD estimates steadily hover around 5 percentage points, none rise to conventional levels of statistical significance. Estimates from the difference-in-differences approach are slightly larger, between 7 and 8 percentage points, and marginally significant. The main concern regarding the causal interpretation of the difference-in-differences estimates is that, since we cannot formally test the parallel trends assumption with one pre-treatment cohort, any subsequent effects might be the results of divergent trends or a time-varying shock correlated with Covenant eligibility and measures of college success and completion (e.g., the Great

\footnotetext{
${ }^{31}$ The similarity of these two estimates is important for two reasons. First, we argue that the difference-indifferences approach anchored on one pre-cohort year (2003) is likely to be more valid for temporally proximate Covenant cohorts and useful in netting out any additional, unobservable student characteristics at the eligibility threshold for the early Covenant cohorts of 2004 to 2006. Second, the analytic sample for the difference-indifferences approach includes a wider range of students and therefore includes students well below the cutoff, whom we might expect to benefit the most from additional grant aid. Thus, the fact that we continue to find no appreciable effect on four-year completion rates with the difference-in-differences approach suggests that grant aid alone, while influential along the extensive margin of college enrollment, may not be as effective in promoting post-enrollment success.
} 
Recession). The fact that our estimates are similar across difference-in-differences specifications that omit and control for student-level covariates is encouraging. Nevertheless, moving forward, we focus our interpretation on estimates from the RD setup.

\section{E. Effects on Progress and Performance}

In Tables 5 and 6, we explore effects of Covenant eligibility on measures of credit accumulation and academic performance. ${ }^{32}$ We generally focus interpretation on estimates from our preferred RD specification in column 4 of each table. Figure 5 presents RD graphs for select outcomes that illustrate representative contrasts in effects (or lack thereof) between the early (2004-2006) and late (2007-2010) groups of cohorts.

The estimate in column 4 of Table 5 shows that Covenant-eligible students in the cohorts of 2007 to 2010, who received institutional grant aid along with robust non-financial supports, were about 7 percentage points more likely to have earned 30 credits one year after initially enrolling in UNC-CH, compared to their barely ineligible counterparts. For the earlier cohorts of Covenant scholars (2004-2006), who received additional grant aid but were exposed to limited non-financial supports, we see no such effect. The pattern of coefficients across the subsequent two credit-based outcomes that track progress toward on-time completion (i.e., within four years of initial enrollment) suggests that the effect of Covenant eligibility on timely credit

\footnotetext{
${ }^{32}$ Early college persistence rates are quite high for all cohorts and we fail to detect effects of Covenant eligibility on persistence for either group of cohorts (see Appendix Table A2). For both sets of outcomes (cumulative earned credits and cumulative GPA), we assign students who drop out or otherwise disappear from the dataset the last cumulative value on record. The outcome that measures cumulative earned credits includes Advanced Placement (AP) and International Baccalaureate (IB) credits earned upon college entry as well as any summer credits earned prior to entering the next year of college. AP and IB credits are a function of pre-treatment high school coursework but also contribute to timely credit accrual during college. Therefore, we include them in our measure of total cumulative earned credits but check to see whether there are any differences at the Covenant eligibility threshold in AP credits: We use AP credits as the outcome in our preferred RD specification (i.e., column 4 of Table 4) and detect no association between Covenant eligibility and the number of AP credits with which a student enters UNC$\mathrm{CH}$. Estimates and standard errors of the discontinuity for the 2004-2006 and 2007-2010 groups of cohorts are $0.686(0.961)$ and $1.009(0.731)$, respectively.
} 
accumulation for the cohorts of 2007 to 2010 persists at least through earning 60 credits by two years after initial enrollment.

Table 6 provides some evidence that Covenant eligibility in the cohorts of 2007 to 2010 bolsters academic performance as students move through college: by three years after initial enrollment, the cumulative GPA of Covenant-eligible students is about 0.09 points higher than their barley ineligible counterparts (which is equivalent to about 15 percent of a standard deviation of the cumulative GPA measure). We see less evidence of such an effect for the early cohorts of 2004 to 2006, but our RD estimates are much more sensitive to the inclusion of controls. $^{33}$

Taken together, the results from Tables 5 and 6 suggest that Covenant eligibility boosts timely credit accrual and academic performance for the cohorts in which Covenant scholars received more institutional grant aid and had access to a suite of non-financial supports. ${ }^{34}$ We see less evidence of such effects in the early cohorts (2004-2006) that received additional grant aid but had access to few non-financial supports. Thus, one plausible interpretation of this set of findings alongside extant literature is that grant-heavy, need-based financial aid affects measures of postsecondary success along the intensive margin differently than it does college enrollment (i.e., the extensive margin). One explanation for such differences in effects is that concerns related to credit constraints and finances dominate students’ and families’ decisions about college-going. But, once enrolled, non-financial barriers such as cultural and academic

\footnotetext{
${ }^{33}$ The corresponding estimate and standard error from a difference-in-differences setup of the effect of Covenant eligibility during the early cohorts of 2004 to 2006 on cumulative GPA three years after initial enrollment is 0.007(0.057). Thus, this is additional evidence of little effect of Covenant eligibility on academic performance for the early cohorts of scholars.

${ }^{34}$ Covenant-eligible students could perform better in the later years of college if they differentially switched to majors with relatively high GPAs. Appendix Table A3 tests this explanation. In this table, we estimate the effect of Covenant eligibility on the likelihood a student's final recorded major is in a STEM field. For the cohorts where we see a GPA effect (2007-2010) we fail to find evidence that students shied away from majors with traditionally low average GPAs. In fact, it appears that Covenant-eligible students in the cohorts of 2007 to 2010 may have been a bit more likely to major in a STEM field than their barely ineligible counterparts.
} 
adjustment frictions, dominate. This is likely to be especially true for first-generation, underrepresented students at elite institutions of higher education.

\section{F. Heterogeneous Effects by Gender}

Given evidence that male and female students respond differently to postsecondary interventions and costs (e.g., Angrist et al., 2009; Garibaldi et al., 2012), we explore heterogeneity in the effects of Covenant eligibility in Table 7. We focus on male-female comparisons within the more recent set of cohorts (2007-2010) for which we find effects on measures of postsecondary progress and performance. Figure 6 presents RD graphs that examine effects of Covenant eligibility on college completion separately for males and females.

The estimates in Table 7 along with visual inspection of Figure 6 suggest that the Covenant program may have boosted college completion much more for males than for females in the cohorts of 2007 to 2010. ${ }^{35}$ In Panel A of Table 7, estimates of the effect of Covenant eligibility on graduating from college in four years are always close to zero in magnitude and statistically insignificant for females. For males, this effect rises to a marginally significant 12 percentage points. Potential underlying mechanisms responsible for these differential completion effects by gender are a bit unclear. Results in Panel B of Table 7 show that the effects on timely credit accumulation are driven by impacts on females whereas estimates in Panel C of Table 7 suggest that Covenant eligibility improved academic performance for both men and women, with potentially larger effects on men. Thus, like Angrist et al. (2009), we see that effects on timely credit accumulation of a program that mixes financial and non-financial supports are driven by women. Yet, we do not see the same pattern with impacts on academic performance throughout college and we find suggestive evidence of a completion effect for men but not women. Angrist

\footnotetext{
${ }^{35}$ Appendix Table A4 presents complementary RD estimates by gender for the early cohorts of 2004 to 2006. We see little evidence of differential completion effects for males versus females. Indeed, the coefficient for males in column 4 is negative and statistically insignificant.
} 
and colleagues (2009) note that women used the non-financial services and supports at much higher rates than men. Unfortunately, the Carolina Covenant program does not track students' usage of the non-financial components. Going forward, a path for future research is to better understand the mechanisms that lead to differential responses of men and women to in-college aid programs that mix financial and non-financial supports in different ways.

\section{Discussion and Conclusion}

We use rich administrative data on college enrollees at a highly selective public institution to study the effects of a need-based, multifaceted, institutional aid program on postsecondary progress, achievement, and completion. Across specifications and approaches, we see little to no evidence that the early version of the Covenant program (2004-2006), in which students were supplied with additional institutional grant aid without much in the way of nonfinancial support, improved progress, performance, or completion. In contrast, the more recent incarnation of the program (2007-2010) layers a range of non-financial supports on top of a grant-heavy aid package. For these cohorts, we find that Covenant eligibility increases the likelihood students stay on track to graduate in four years by accumulating the necessary number of credits by key time points. In addition, we see some evidence that Covenant eligibility improves students' academic performance in college.

In the end, we fail to detect statistically significant effects of Covenant eligibility on rates of four-year college completion for either set of cohorts. Yet, a few associated findings point to suggestive evidence of a positive effect for the recent cohorts of 2007 to $2010 .{ }^{36}$ First, we find statistically significant effects on intermediate outcomes such as timely credit accumulation and

\footnotetext{
${ }^{36}$ In addition, since the character of the financial treatment in the later cohorts is largely a substitution of grants for loans, the expected reduction in debt for Covenant-eligible students may also affect post-college employment decisions. Rothstein and Rouse (2011) find that debt increases the likelihood college graduates choose higher-paying jobs and reduces their propensity to enter "public interest" jobs.
} 
cumulative GPA that could lead to improved completion. Second, if we include even needier students farther below the eligibility threshold in the context of the alternative difference-indifferences approach, our estimate of the effect of Covenant eligibility on four-year graduation rates rises from an insignificant 5 percentage points to a marginally significant 7 percentage points for the cohorts that received both grant aid and robust non-financial supports (2007-2010), but remains close to zero and statistically insignificant for the early cohorts that received grant aid and limited non-financial supports (2004-2006).

Taken together, our core findings highlight the importance of non-financial supports for students after they enroll in college. In this sense, our findings are consonant with those of Angrist et al. (2009) and Scott-Clayton (2011) who, in different ways for different populations of students, find that financial support alone is unlikely to boost college success. Our evidence strengthens the general external validity of the conclusion that money is a necessary but insufficient condition to improve postsecondary outcomes, especially for underrepresented students, as it comes from a setting (elite public institution) and sample (low-income, largely first-generation students) that differ from both of these prior studies. Further, our results expand the conversation concerning the nature of such "non-financial supports.” For example, ScottClayton (2011) argues that her findings point to the use of "incentives tied to minimum course loads (not just GPAs)” (p. 644) as one promising strategy for boosting educational attainment. Our results suggest that, at least for some populations of students in some settings, a looser array of non-financial supports focused on academic, cultural, and social adaptation to college may also improve post-enrollment college outcomes. The stronger and more comprehensive suite of non-financial supports to which the more recent set of Covenant cohorts (2007-2010) were exposed included peer mentoring, learning disability services, opportunities to dine with fellow 
scholars and administrators, and the provision of a rich array of low- or no-cost on-campus cultural experiences. The costs associated with supplying these non-financial components were about \$276,000 per year (in 2010 dollars). This figure includes stipends for faculty mentors and office administrative support as well as the costs of all special programming activities and subsidies. Thus, this translates to a cost of roughly $\$ 580$ per Covenant-eligible student. ${ }^{37}$ This interpretation of our findings is consistent with recent portrayals of barriers encountered by low-income, first-generation students at strong postsecondary institutions (e.g., Pappano, 2015). These anecdotes make the case that financial aid can get such students in the door, but once enrolled these students confront barriers beyond the financial. Such barriers are depicted as social, cultural, and complicated: "The bright children of janitors and nail salon workers, bus drivers and fast-food cooks may not have grown up with the edifying vacations, museum excursions, daily doses of NPR and prep schools that groom Ivy applicants...” (Pappano, 2015). It is exactly these types of barriers the non-financial aspects of the Carolina Covenant were designed to address. Our work suggests such supports have the capacity to improve the postsecondary progress and performance of low-income, underrepresented students at highly competitive institutions when layered on top of need-based, grant-heavy aid.

\footnotetext{
${ }^{37}$ We base this figure on an average of the sizes of the incoming Covenant-eligible cohorts from 2007 through 2010, available in Table 1.
} 


\section{References}

Angrist, J., Lang, D., \& Oreopoulos, P. (2009). Incentives and services for college achievement: Evidence from a Randomized Trial. American Economic Journal: Applied Economics, 1(1), 136-163.

Bailey, M., \& Dynarski, S. (2011). Inequality in postsecondary attainment. In Greg Duncan and Richard Murnane (Eds.), Whither Opportunity: Rising Inequality, Schools, and Children's Life Chances, pp. 117-132. New York, NY: Russell Sage Foundation.

Barreca, A. I., Lindo, J. M., \& Waddell, G. R. (2011). Heaping-induced bias in regressiondiscontinuity designs. NBER Working Paper, No. 17408. Access: http://www.nber.org/papers/w17408.pdf

Baum, S., Ma, J., \& Payea, K. (2013). Education pays: The benefits of higher education for individuals and society. The College Board. Access: https://trends.collegeboard.org/sites/default/files/education-pays-2013-full-report.pdf

Bettinger, E. P., \& Baker, R. B. (2014). The effects of student coaching: An evaluation of a randomized experiment in student advising. Educational Evaluation and Policy Analysis, 36(1), 3-19.

Bettinger, E. P., Long, B. T., Oreopoulos, P., \& Sanbonmatsu, L. (2012). The role of application assistance and information in college decisions: Results from the H\&R Block FAFSA experiment. Quarterly Journal of Economics, 127(3), 1205-1242.

Bettinger, E. P. (2004). How financial aid affects persistence. In C. M. Hoxby (Ed.), College choices: The economics of where to go, when to go, and how to pay for it (pp. 207-238). Cambridge, MA: National Bureau of Economic Research.

Bowen, W. G., Chingos, M. M., \& McPherson, M. S. (2009). Crossing the finish line: Completing college at America's public universities. Princeton, NJ: Princeton University Press.

Bruce, D. J., \& Carruthers, C. K. (2014). Jackpot? The impact of lottery scholarships on enrollment in Tennessee. Journal of Urban Economics, 81, 30-44.

Calonico, S., Cattaneo, M. D., \& Titiunik, R. (2015). Optimal data-driven regression discontinuity plots. Journal of the American Statistical Association, 110(512), 17531769.

Calonico, S., Cattaneo, M. D., \& Titiunik, R. (2014). Robust data-drive inference in the regression-discontinuity design. The Stata Journal, 14(4), 909-946. 
Castleman, B. L., \& Page, L. C. (2015). Freshman year financial aid nudges: An experiment to increase FAFSA renewal and college persistence. Journal of Human Resources, 51(2), forthcoming.

Castleman, B. L., \& Long, B. T. (2013). Looking beyond enrollment: The causal effect of needbased grants on college access, persistence, and graduation. NBER Working Paper, No. 19306. Access: http://www.nber.org/papers/w19306

Castleman, B. L., \& Page, L. C., \& Schooley, K. (2014). The forgotten summer: Does the offer of college counseling after high school mitigate summer melt among college-intending, low-income high school graduates? Journal of Policy Analysis and Management, 33(2), 320-344.

College Board. (2009). Research Notes: ACT and SAT Concordance Tables. Access: https://research.collegeboard.org/sites/default/files/publications/2012/7/researchnote2009-40-act-sat-concordance-tables.pdf

Deming, D. \& Dynarski, S. (2010). Into college, out of poverty? Policies to increase postsecondary attainment of the poor. In Phillip B. Levine \& David J. Zimmerman (Eds.), Targeting Investments in Children: Fighting Poverty When Resources are Limited, pp. 382-402.

Dynarski, S., \& Scott-Clayton, J. (2013). Financial aid policy: Lesson from research. Future of Children, 23(1), 67-91.

Dynarski, S. (2008). Building the stock of college-educated labor. Journal of Human Resources, 43(3), 576-610.

Dynarski, S. M. (2003). Does aid matter? Measuring the effect of student aid on college attendance and completion. American Economic Review, 93(1), 279-288.

Fiske, E. B. (2010). “The Carolina Covenant.” In R. D. Kahlenberg, ed., Rewarding Strivers: Helping Low-Income Students Succeed in College. The Century Foundation Press.

Fitzpatrick, M., \& Jones, D. (2012). Higher education, merit-based scholarships and postbaccalaureate migration. NBER Working Paper Series, No. 18530. Access: http://www.nber.org/papers/w18530

Garibaldi, P., Giavazzi, F., Ichino, A., \& Rettore, E. (2012). College cost and time to complete a degree: Evidence from tuition discontinuities. Review of Economics and Statistics, 94(3), 699-711.

Heller, D. E. (1997). Student price response in higher education: An update to Leslie and Brinkman. The Journal of Higher Education, 68(6), 624-659. 
Hemelt, S. W., \& Marcotte, D. E. (2011). The impact of tuition increases on enrollment at public colleges and universities. Educational Evaluation and Policy Analysis, 33(4), 435-457.

Hoekstra, M. (2009). The effect of attending the flagship state university on earnings: a discontinuity-based approach. Review of Economics and Statistics, 91(4), 717-724.

Hoxby, C. \& Turner, S. (2014). Expanding opportunities for high-achieving, low-income students. Stanford Institute for Economic Policy Research (SIEPR) Working Paper, No. 12-014. Access: http://siepr.stanford.edu/publicationsprofile/2555

Hoxby, C., \& Avery, C. (2013). The missing “one-offs”: The hidden supply of high-achieving, low-income students. Brookings Papers on Economic Activity, Spring 2013. Access: http://www.brookings.edu/ /media/projects/bpea/spring-2013/2013a_hoxby.pdf

Kane, T. J. (1995). Rising public college tuition and college entry: How well do public subsidies promote access to college? NBER Working Paper Series, No. 5164.

Lee, D. S., \& Lemieux, T. (2009). Regression discontinuity designs in economics. NBER Working Paper Series, No. 14723, access: http://www.nber.org/papers/w14723

McCrary, J. (2008). Manipulation of the running variable in the regression discontinuity design: A density test. Journal of Econometrics, 142(2), 398-714.

NASSGAP. (2014). 44 ${ }^{\text {th }}$ Annual Survey Report on State-Sponsored Financial Aid. National Association of State Student Grant Aid Programs. Access: https://www.nassgap.org/viewrepository.aspx?categoryID=3\#

Page, L. C., Castleman, B. L., \& Sahadewo, G. A. (2016). More than dollars for scholars: The impact of the Dell Scholars Program on college access, persistence and degree attainment. Working paper, access: http://papers.ssrn.com/sol3/papers.cfm?abstract_id=2726320

Page, L., C., \& Scott-Clayton, J. (2015). Improving college access in the United States: Barriers and policy responses. NBER Working Paper Series, No. 21781. Access: http://www.nber.org/papers/w21781

Pappano, L. (2015, April 8). First-generation college students unite. The New York Times, Education Life, p. ED18.

Rothstein, J., \& Rouse, C. E (2011). Constrained after college: Student loans and early-career occupational choices. Journal of Public Economics, 149-163.

Scott-Clayton, J. (2010). On money and motivation: A quasi-experimental analysis of financial incentives for college achievement. Journal of Human Resources, 46(3), 614-646. 
Scrivener, S., et. al. (2015). Doubling graduation rates: Three-year effects of CUNY's Accelerated Study in Associate Programs (ASAP) for developmental education students. MDRC Research Report, Access: http://www.mdrc.org/publication/doubling-graduation$\underline{\text { rates }}$

Scrivener, S., \& Weiss, M. J. (2009). More guidance, better results? Three-year effects of an enhanced students services program at two community colleges. MDRC Research Report, Access: http://www.mdrc.org/sites/default/files/full_450.pdf

Sjoquist, D. L., \& Winters, J. V. (2012). Building the stock of college-educated labor revisited. Journal of Human Resources, 49, 572-610. 


\section{Figure 1. Distribution of Running Variable}

A. All Cohorts, 2004-2010

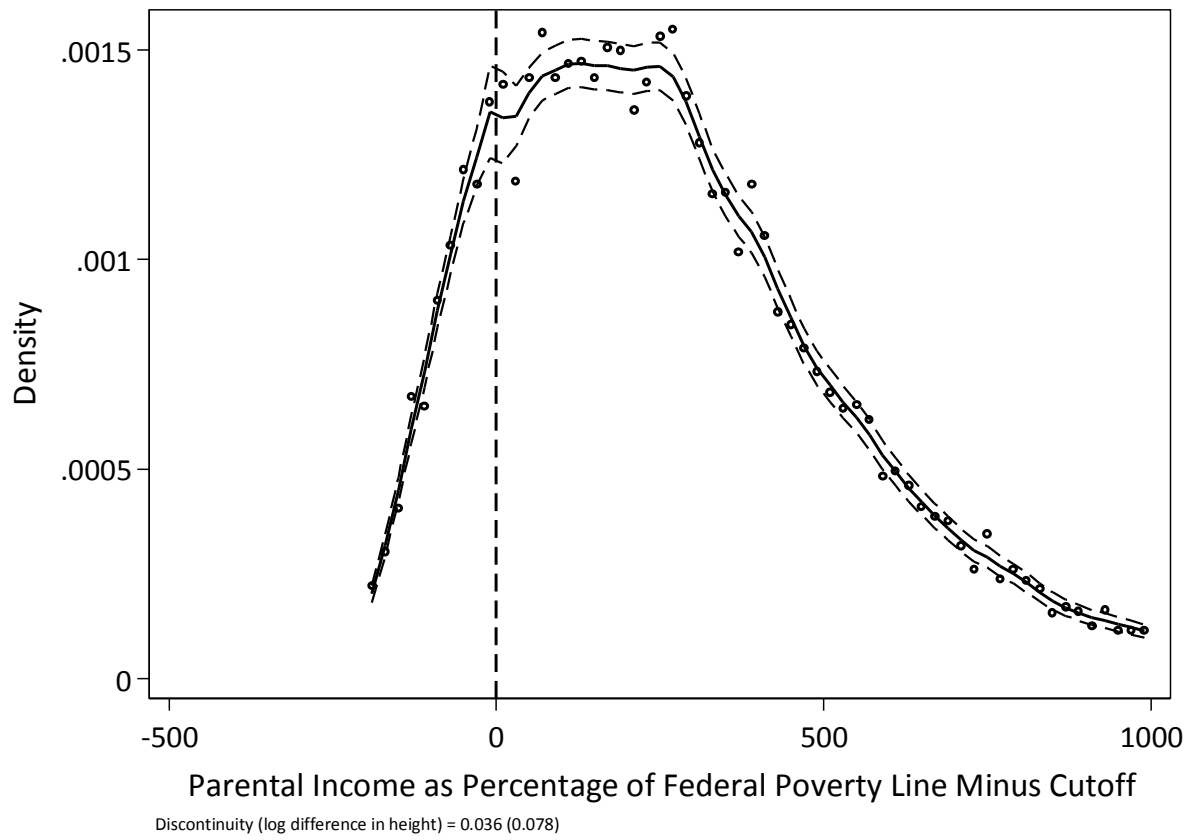

B. Early vs. Late Cohorts
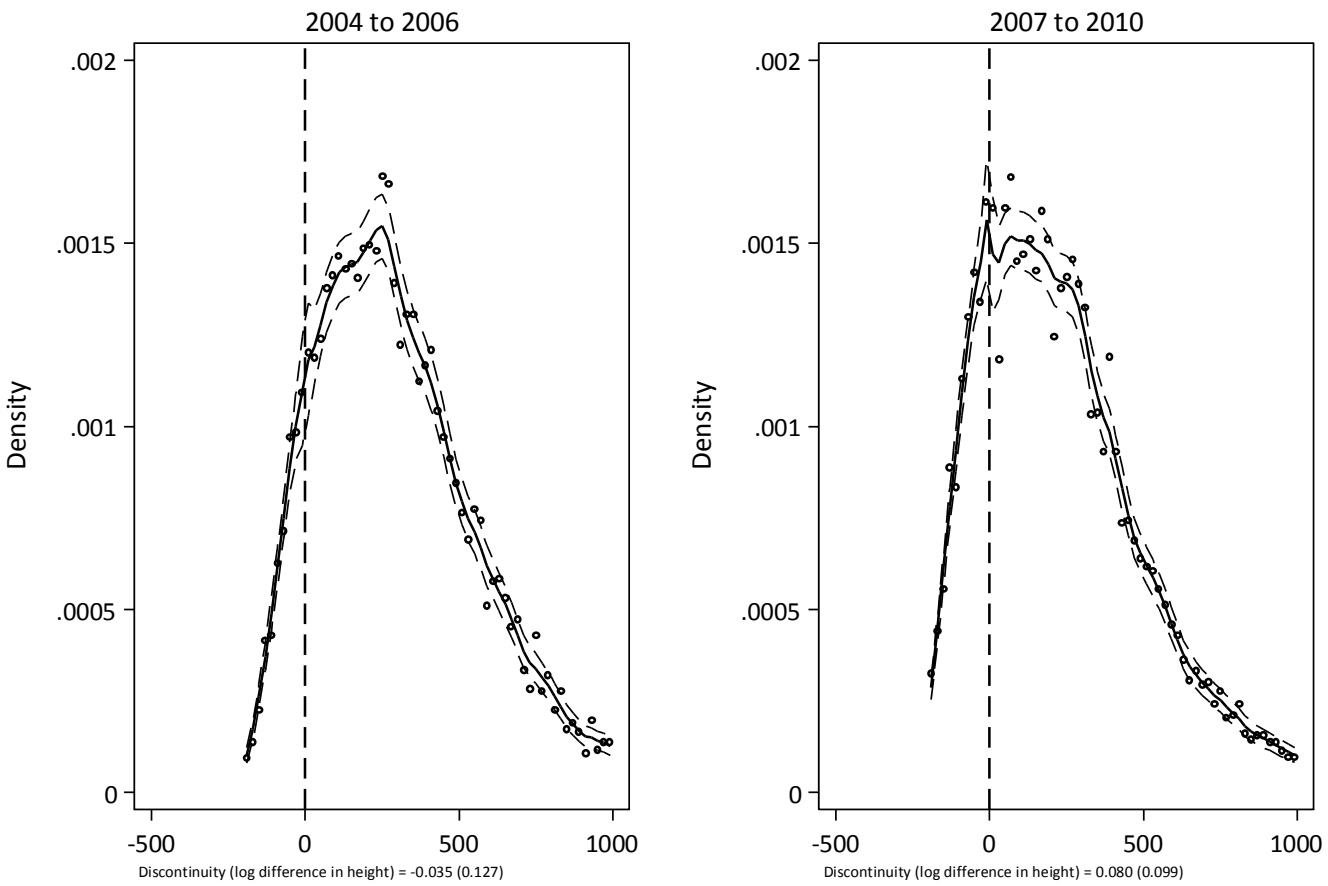

Family Income as Percentage of Poverty Line Minus Cutoff

Notes: Graphs depicts McCrary (2008) test for discontinuity in the density of the running variable at the cutoff for Covenant eligibility; bandwidth $=75$. 
Figure 2. Covariate Balance: Early vs. Late Cohorts

\section{A. Pre-College Achievement: SAT Score}
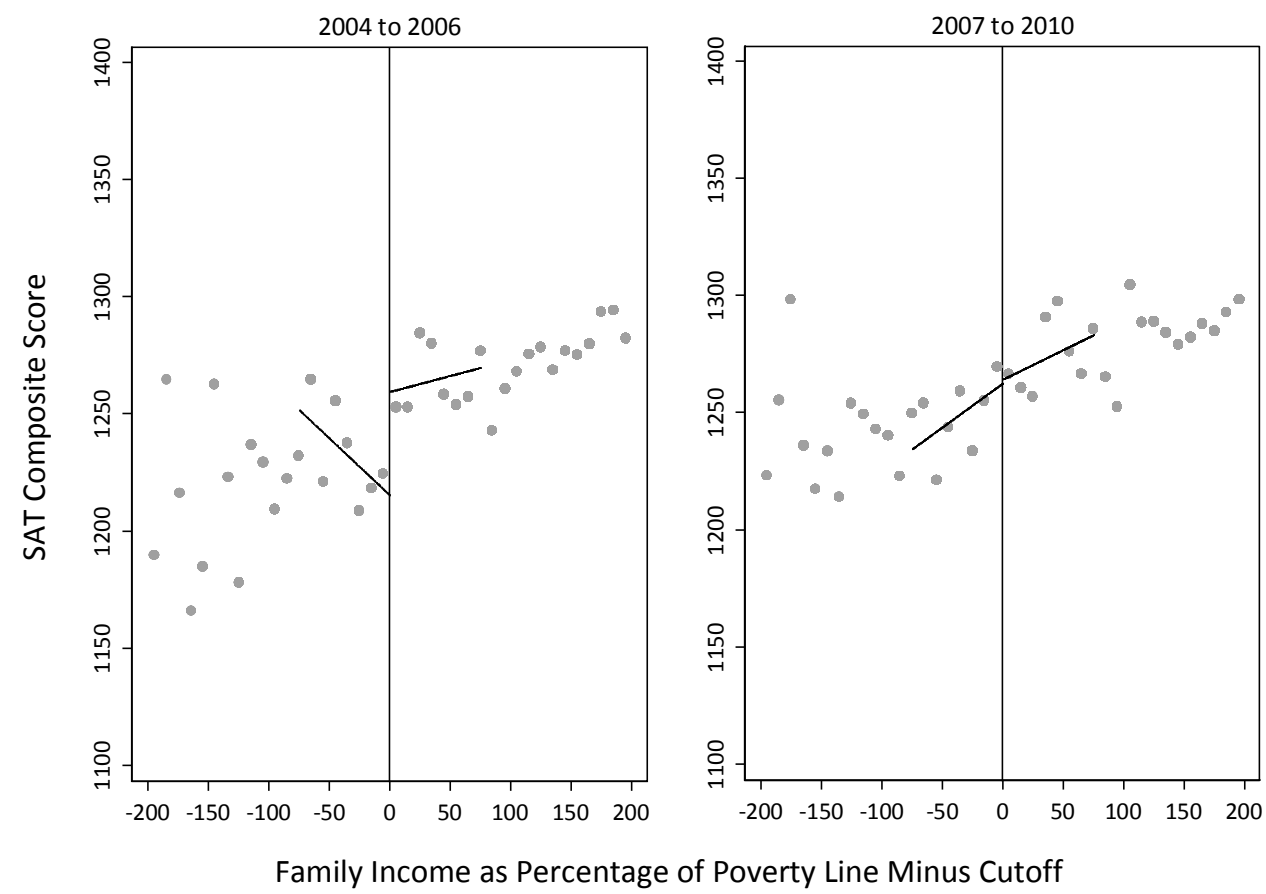

\section{B. Demographics: Share White, Non-Hispanic}
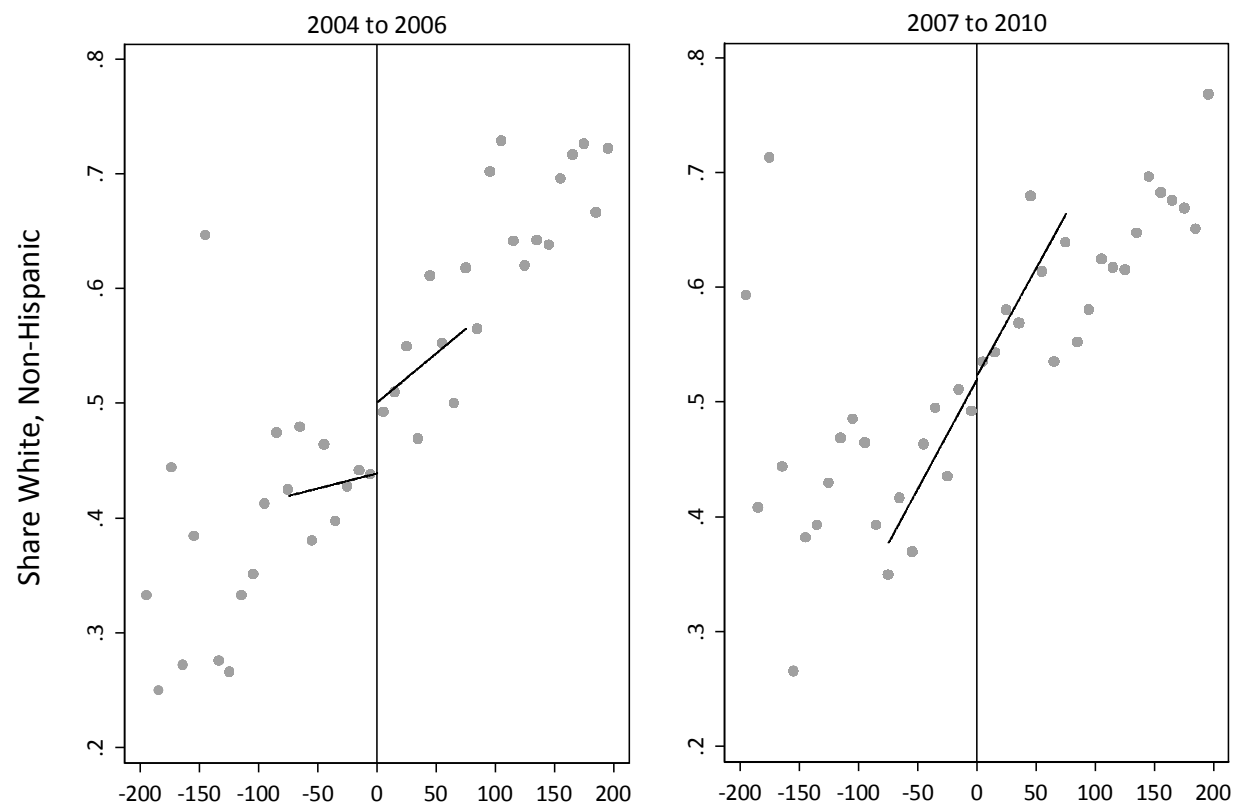

Family Income as Percentage of Poverty Line Minus Cutoff

Notes: Solid lines represent local linear regressions within a data window of $+/-75$ of the cutoff using a rectangular kernel. Appendix Table A1 presents a range of parametric and nonparametric estimates of the discontinuities at the cutoff. 
Figure 3. Treatment-Control Contrast: Financial Aid Elements, Early vs. Late Cohorts

A. Total Aid
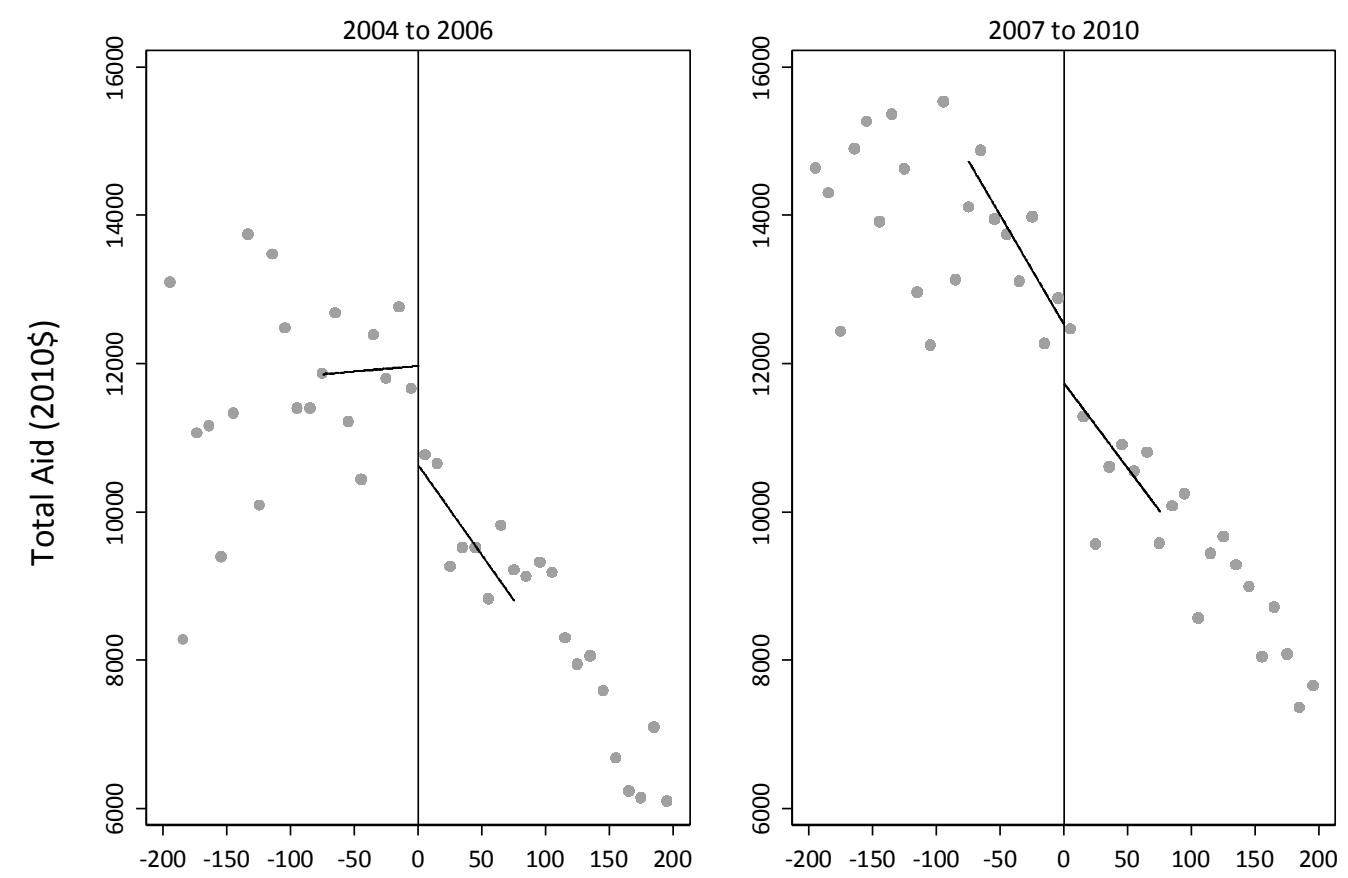

Family Income as Percentage of Poverty Line Minus Cutoff

\section{B. Loans Amount}
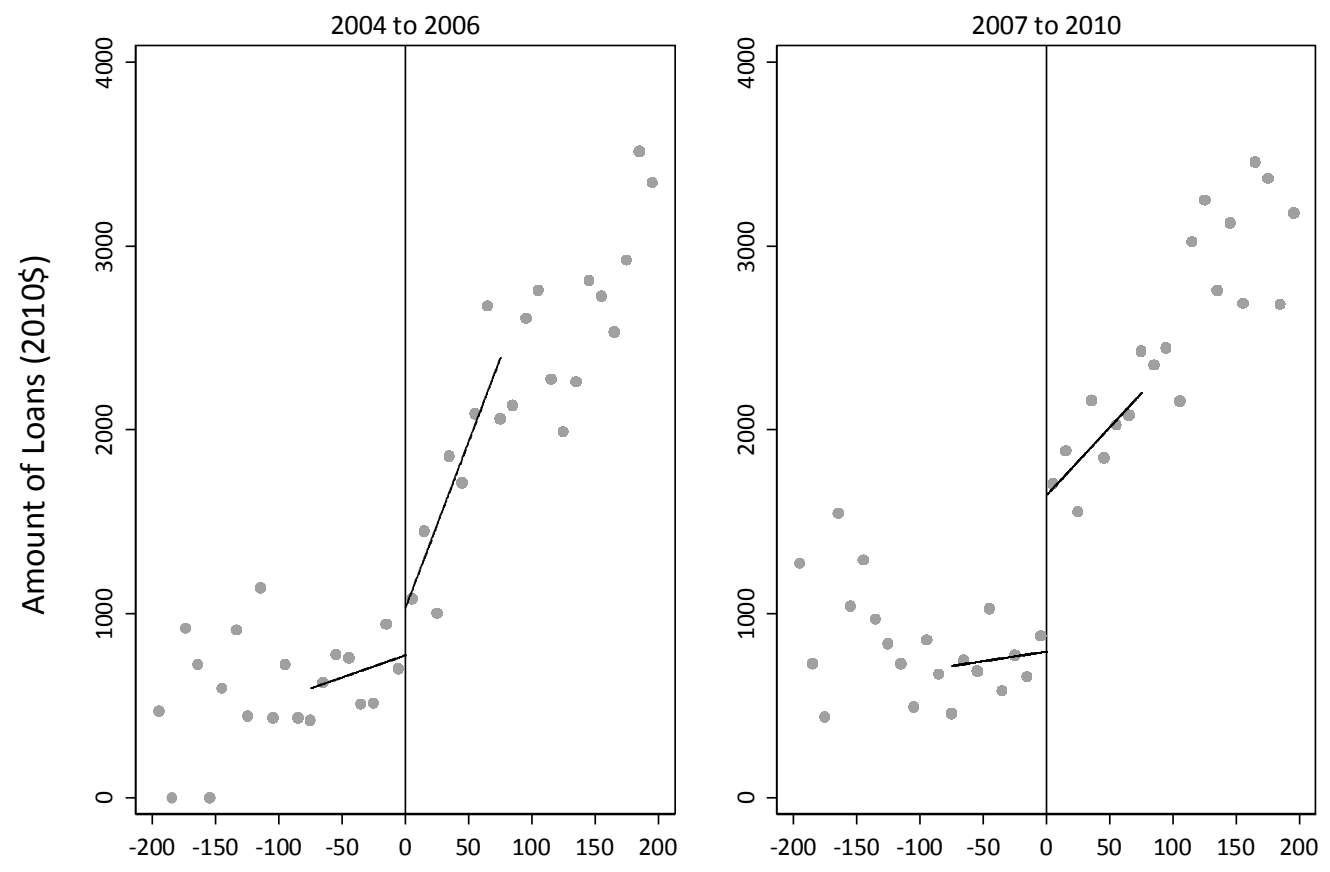

Family Income as Percentage of Poverty Line Minus Cutoff 


\section{Institutional, Need-Based Grant Aid Amount (2010\$)}
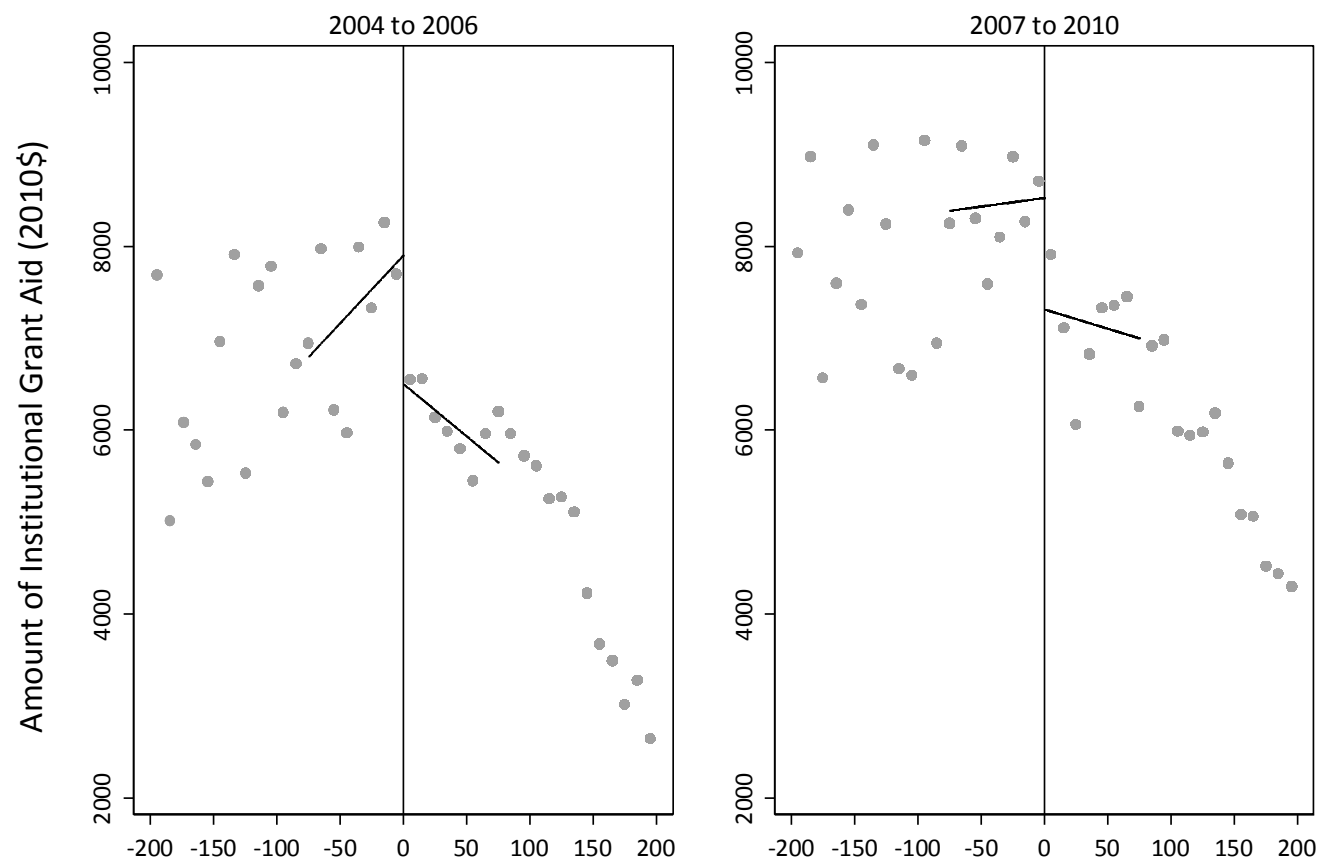

Family Income as Percentage of Poverty Line Minus Cutoff

Notes: Solid lines represent local linear regressions within a data window of +/- 75 of the cutoff using a rectangular kernel. See Table 3 for the corresponding point estimates of the discontinuities. 
Figure 4. Effects of Covenant Eligibility on College Completion

A. 4-Year College Completion Rate, Early Cohorts, 2004-2006

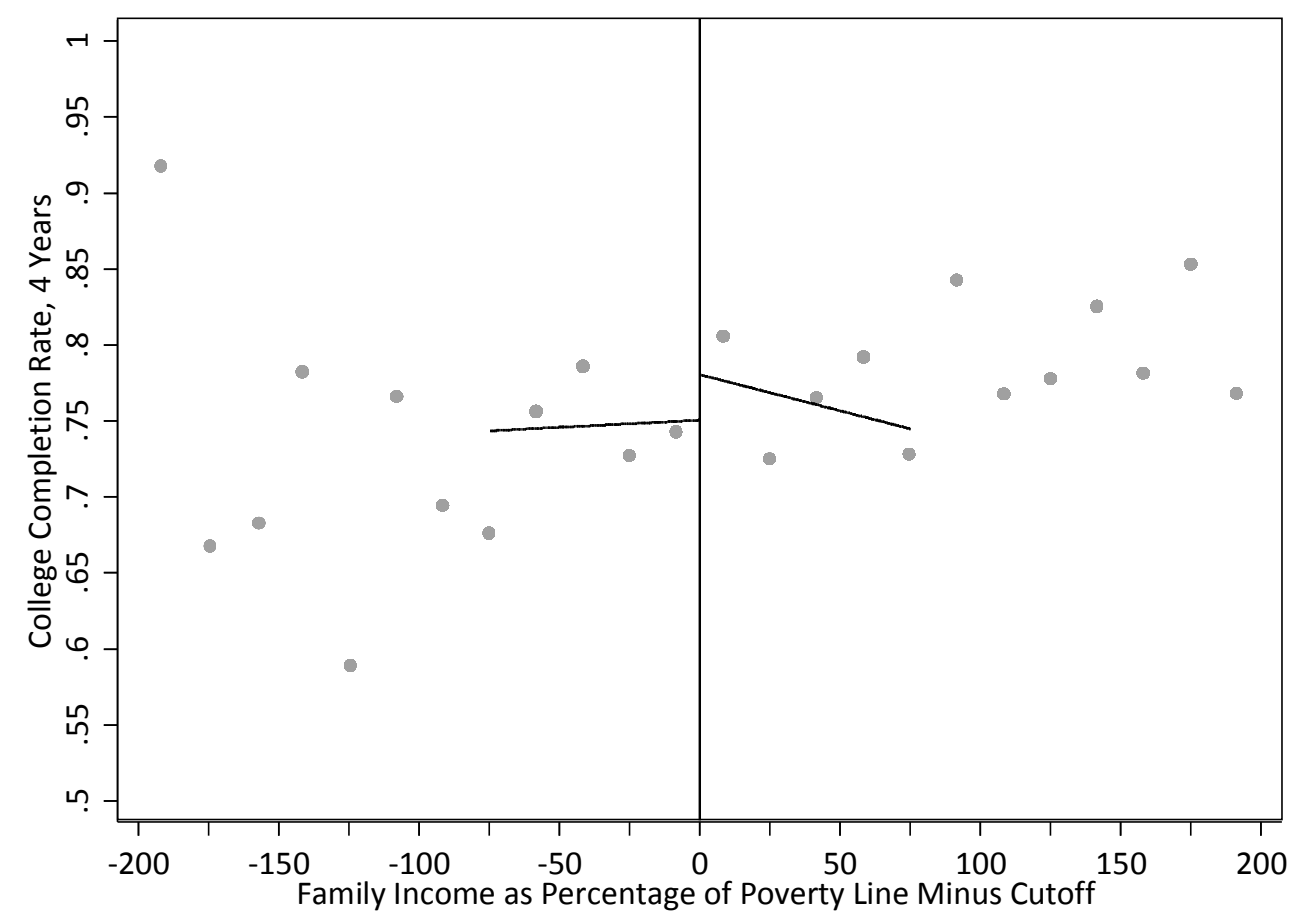

B. 4-Year College Completion Rate, Late Cohorts, 2007-2010

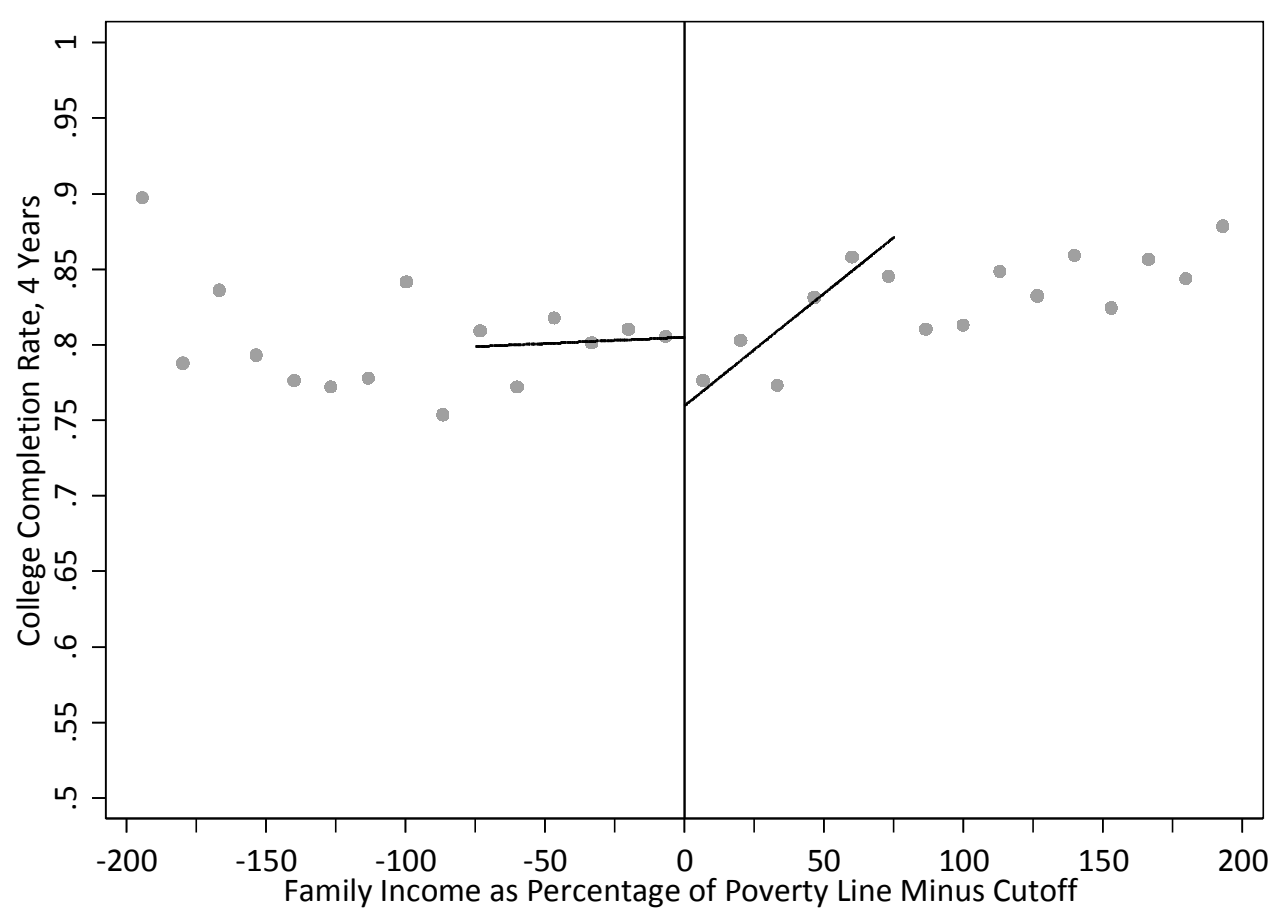

Notes: Solid lines represent local linear regressions within a data window of $+/-75$ of the cutoff using a rectangular kernel. See Table 4 for a range of parametric and nonparametric estimates of the discontinuities. 
Figure 5. Effects of Covenant Eligibility on Postsecondary Progress and Performance

\section{A. Earned 30 Credits 1 Year After Enrollment}
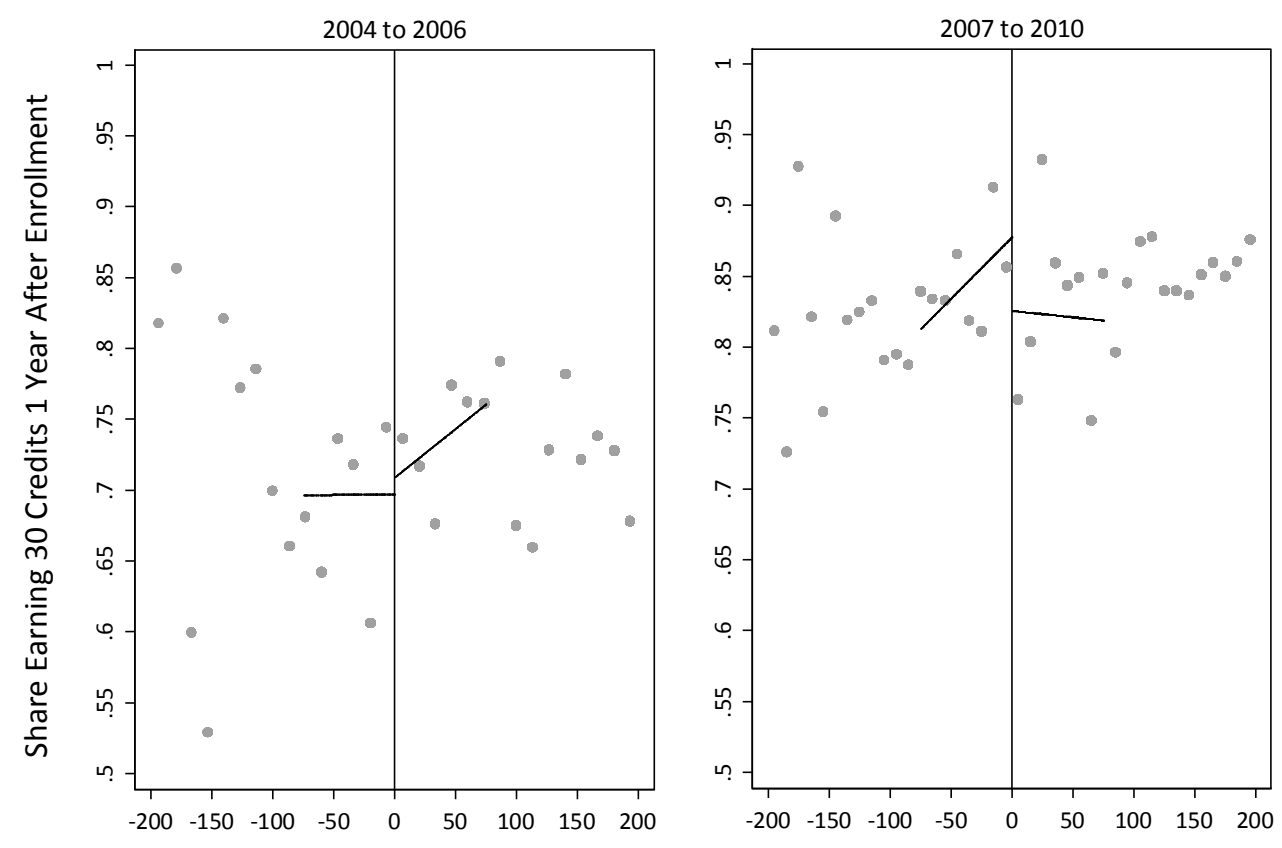

Family Income as Percentage of Poverty Line Minus Cutoff

\section{B. Cumulative GPA 3 Years After Enrollment}
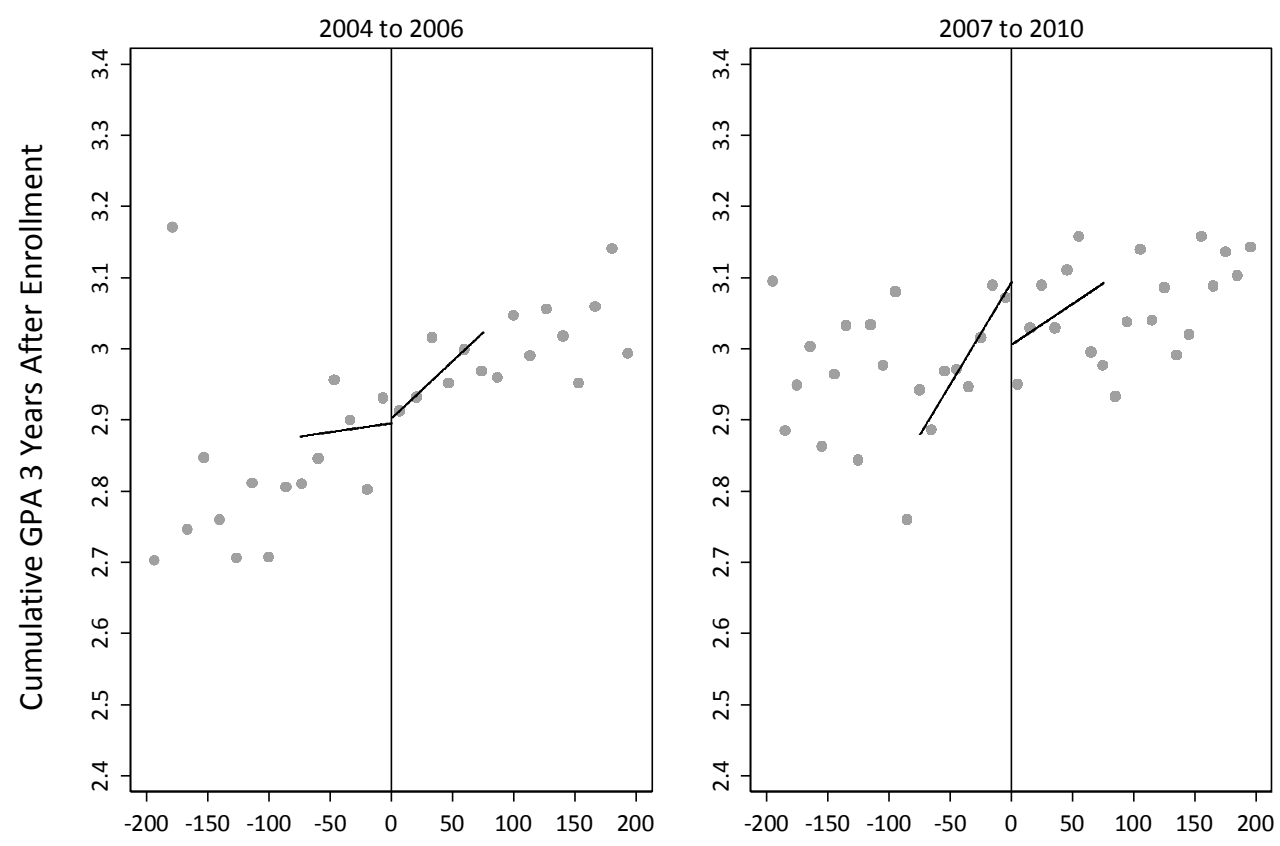

Family Income as Percentage of Poverty Line Minus Cutoff

Notes: Solid lines represent local linear regressions within a data window of +/- 75 of the cutoff using a rectangular kernel. See Tables 5 and 6 for a range of parametric and nonparametric estimates of the discontinuities. 
Figure 6. Heterogeneous Effects of Covenant Eligibility on College Completion by Gender: Cohorts 2007-2010

A. Male

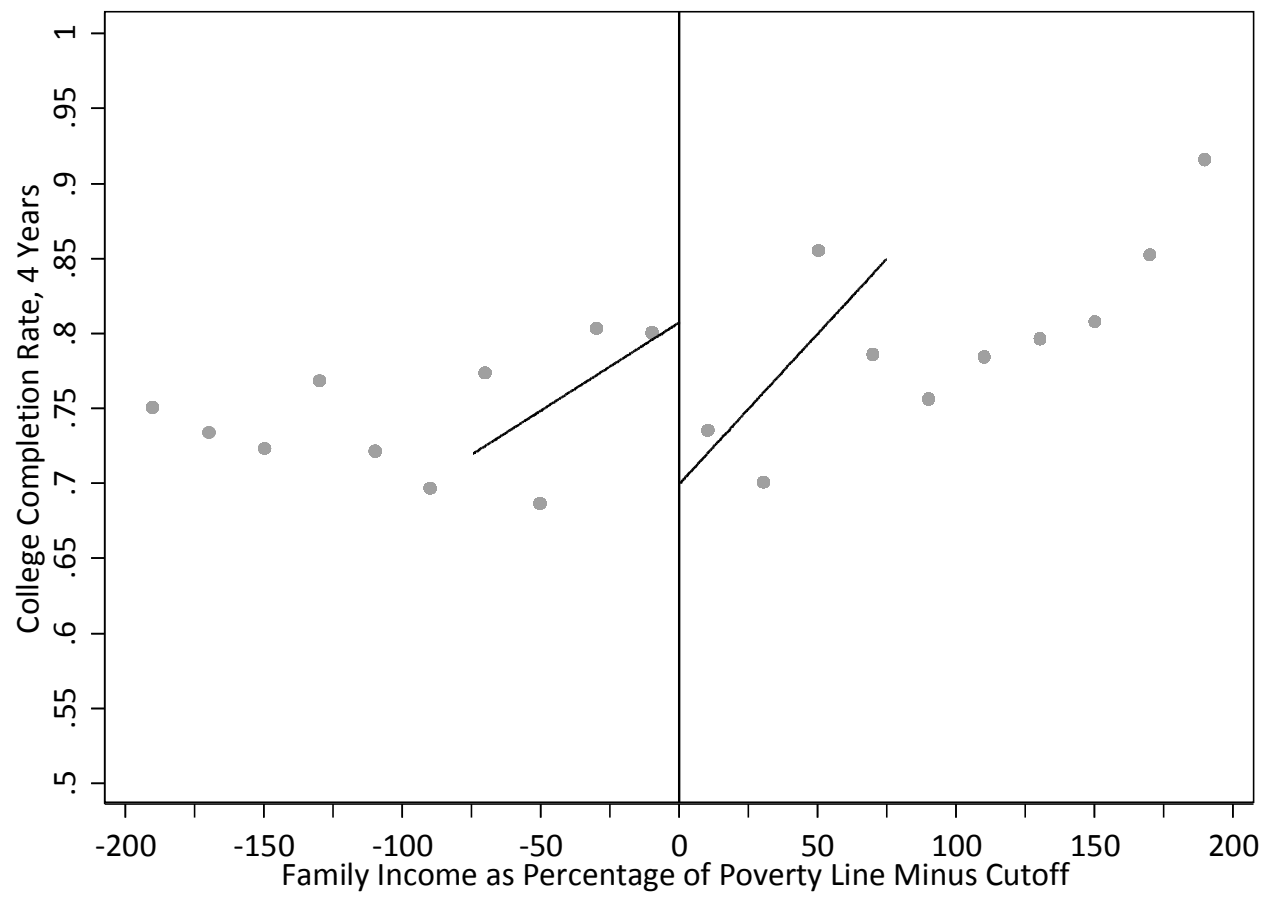

B. Female

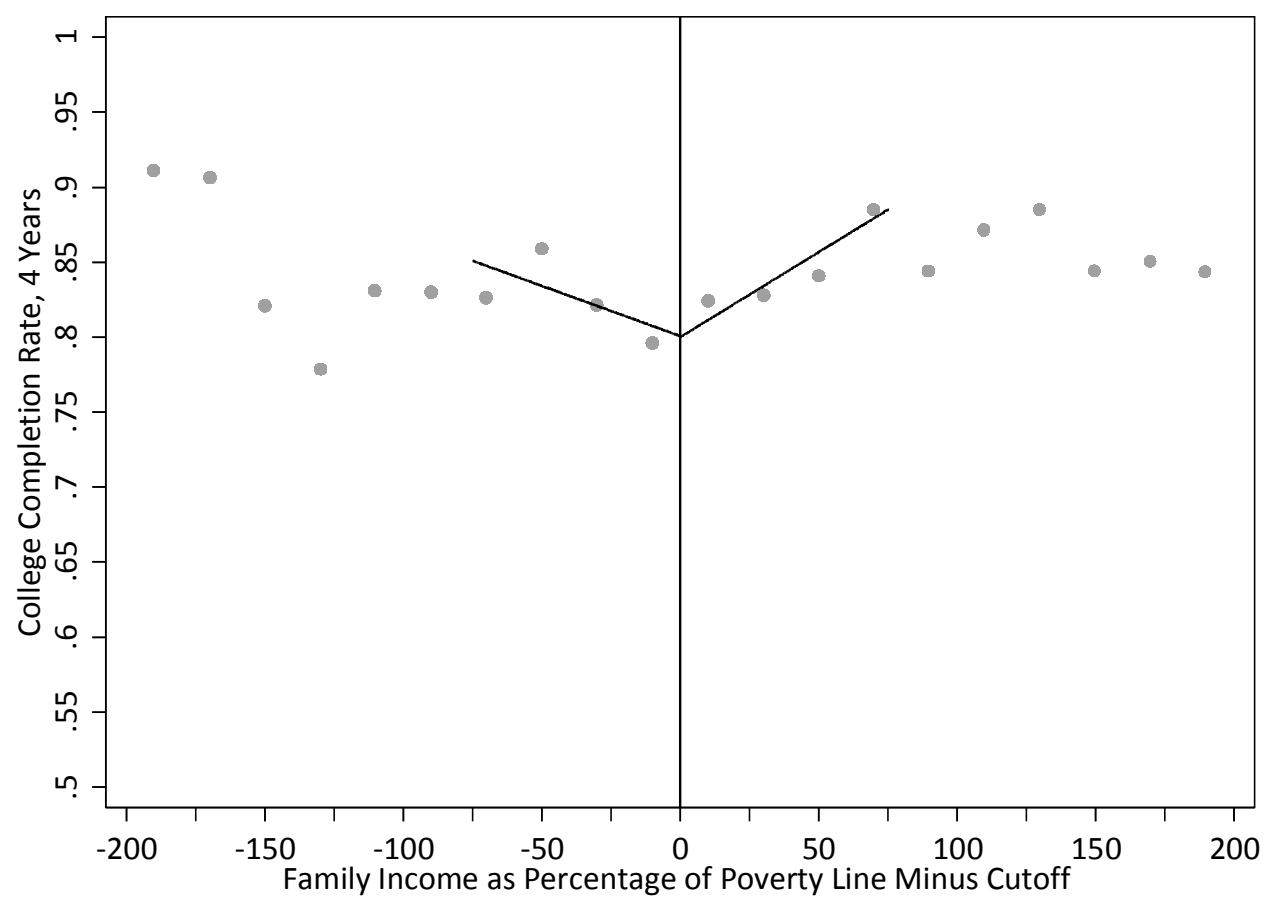

Notes: Solid lines represent local linear regressions within a data window of +/- 75 of the cutoff using a rectangular kernel. See Table 7 for a range of parametric and nonparametric estimates of the discontinuities. 
Table 1. Number of UNC-CH Students Eligible for Carolina Covenant: Estimated and Actual

\begin{tabular}{|c|c|c|c|c|c|c|c|}
\hline \multirow[b]{3}{*}{ Year (Fall) } & \multirow{2}{*}{\multicolumn{2}{|c|}{$\begin{array}{l}\text { Estimated First-Year Students } \\
\text { Income Cutoff for Eligibility }\end{array}$}} & \multirow{3}{*}{ All } & \multicolumn{3}{|c|}{ Actual } & \multirow{3}{*}{$\begin{array}{l}\text { Share NC } \\
\text { Residents }\end{array}$} \\
\hline & & & & $\begin{array}{l}\text { First-Year } \\
\text { Students }\end{array}$ & Transfers & Share First & \\
\hline & $\begin{array}{c}<150 \% \text { Federal } \\
\text { Poverty Level }\end{array}$ & $\begin{array}{c}<200 \% \text { Federal } \\
\text { Poverty Level }\end{array}$ & & & & & \\
\hline 2003 & 153 & & N/A & N/A & $\overline{\mathrm{N} / \mathrm{A}}$ & $\overline{\mathrm{N} / \mathrm{A}}$ & N/A \\
\hline 2004 & 183 & & 224 & 224 & 0 & 0.54 & 0.88 \\
\hline 2005 & & 291 & 351 & 325 & 26 & 0.52 & 0.88 \\
\hline 2006 & & 307 & 413 & 340 & 73 & 0.57 & 0.84 \\
\hline 2007 & & 328 & 397 & 337 & 60 & 0.59 & 0.87 \\
\hline 2008 & & 356 & 409 & 349 & 60 & 0.60 & 0.85 \\
\hline 2009 & & 453 & 530 & 440 & 90 & 0.56 & 0.86 \\
\hline 2010 & & 493 & 558 & 450 & 108 & 0.55 & 0.80 \\
\hline
\end{tabular}

Notes: Analytic sample captures first-time, dependent, fall enrollees in UNC-CH. The first cohort of Covenant scholars entered UNC-CH in the fall of 2004.

Federal poverty level cutoffs take into account family size and are based on parents' adjusted gross earnings for the prior year. See text for details about eligibility. 
Table 2. Descriptive Statistics: Cohorts 2003 to 2010

\begin{tabular}{lccc}
\hline & All Students & $\begin{array}{c}\text { Covenant- } \\
\text { Eligible } \\
\text { Students }\end{array}$ & $\begin{array}{c}\text { Covenant- } \\
\text { Ineligible } \\
\text { Students }\end{array}$ \\
\hline \hline Demographics & & & \\
Female & 0.62 & 0.64 & 0.62 \\
Black, non-Hispanic & 0.14 & 0.28 & 0.12 \\
Hispanic & 0.06 & 0.09 & 0.05 \\
Asian, non-Hispanic & 0.08 & 0.14 & 0.07 \\
White, non-Hispanic & 0.67 & 0.44 & 0.71 \\
Other race/ethnicity, non-Hispanic & 0.04 & 0.05 & 0.04 \\
& & & \\
Pre-College Achievement & & & 4.31 \\
High School GPA & 4.30 & 4.25 & $(0.75)$ \\
SAT Composite Score & $(0.75)$ & $(0.75)$ & 1300 \\
& 1291 & 1238 & $(124)$ \\
Family Background & $(127)$ & $(136)$ & \\
Income (in 2010 dollars) & & & 121,365 \\
Income (as \% of poverty line) & & & $(80,014)$ \\
Household size & 107,251 & 26,134 & 566.34 \\
& $(81,369)$ & $(12,402)$ & $(355.23)$ \\
N(students) & 500.52 & 122.26 & 4.05 \\
\hline
\end{tabular}

Notes: Sample is limited to observations with non-missing demographic and achievement measures. Means are presented for each variable and sample with standard deviations for continuous variables shown below the means in parentheses. Parental income is expressed in real (2010) dollars using the Consumer Price Index for All Urban Consumers (CPI-U). 
Table 3. Effects of Covenant Eligibility on Components of First-Year Financial Aid Package: RD Estimates

\begin{tabular}{|c|c|c|c|c|c|}
\hline Outcome Type and Cohort Group & $\begin{array}{c}\text { Total Aid } \\
\text { (1) }\end{array}$ & $\begin{array}{c}\text { Loans } \\
\text { (2) }\end{array}$ & $\begin{array}{c}\text { Institutional, Need- } \\
\text { Based Grants } \\
\text { (3) }\end{array}$ & $\begin{array}{c}\text { Work Study } \\
\text { (4) }\end{array}$ & $\begin{array}{c}\text { Pell Grant } \\
\text { (5) }\end{array}$ \\
\hline \multicolumn{6}{|l|}{ A. Presence of Aid Component in First-Year Package } \\
\hline \multirow[t]{2}{*}{ Covenant eligible, $2004-2006$} & -- & -0.054 & -0.023 & -0.019 & -0.032 \\
\hline & -- & $(0.053)$ & $(0.034)$ & $(0.059)$ & $(0.045)$ \\
\hline \multirow[t]{2}{*}{ Covenant eligible, 2007-2010 } & -- & $-0.158 * * *$ & 0.002 & -0.015 & 0.013 \\
\hline & -- & $(0.043)$ & $(0.023)$ & $(0.043)$ & $(0.036)$ \\
\hline \multicolumn{6}{|l|}{ B. Amount of Aid Component in First-Year Package } \\
\hline \multirow[t]{2}{*}{ Covenant eligible, $2004-2006$} & $1341 *$ & -258 & $1404^{* *}$ & -99 & $294 *$ \\
\hline & $(767)$ & $(238)$ & $(664)$ & $(120)$ & $(172)$ \\
\hline \multirow[t]{2}{*}{ Covenant eligible, 2007-2010 } & 790 & $-852 * * *$ & $1215^{* *}$ & -29 & $456 * * *$ \\
\hline & $(709)$ & $(233)$ & $(600)$ & $(80)$ & $(141)$ \\
\hline N(students, 2004-2006) & 1133 & 1133 & 1133 & 1133 & 1133 \\
\hline Outcome mean for control group, 2004-2006, Any & -- & 0.42 & 0.88 & 0.34 & 0.58 \\
\hline Outcome mean for control group, 2004-2006, Amount & $\$ 9,591$ & $\$ 1,730$ & $\$ 6,062$ & $\$ 603$ & $\$ 1,301$ \\
\hline N(students, 2007-2010) & 1838 & 1838 & 1838 & 1838 & 1838 \\
\hline Outcome mean for control group, 2007-2010, Any & -- & 0.43 & 0.93 & 0.28 & 0.56 \\
\hline Outcome mean for control group, 2007-2010, Amount & $\$ 10,846$ & $\$ 1,932$ & $\$ 7,150$ & $\$ 462$ & $\$ 1,303$ \\
\hline
\end{tabular}

Notes: The analytic sample for the RD analyses includes the cohorts of 2004 to 2010 . The data window for all outcomes is $+/-75$ of the running variable. We interact the function of the running variable with the indicator for Covenant eligibility. Total aid is defined as the sum of aid from the Pell Grant, institutional grants, loans (including federal, state, institutional, and other), and work study. All aid amounts are expressed in real, 2010 dollars. Results in the table come from estimating a linear, parametric RD model within a data window of $+/-75$ of the cutoff. Robust standard errors appear in parentheses. $* * * \mathrm{p}<0.01,{ }^{* *} \mathrm{p}<0.05, * \mathrm{p}<0.10$. 
Table 4. Effects of Covenant Eligibility on College Completion

\begin{tabular}{|c|c|c|c|c|c|c|c|}
\hline \multirow[b]{4}{*}{ Cohort Group } & \multicolumn{7}{|c|}{ Outcome $=$ Complete college in 4 years } \\
\hline & \multirow[b]{3}{*}{$(1)$} & \multicolumn{3}{|c|}{ RD Estimates } & \multirow{3}{*}{$\begin{array}{c}\text { Nonparametric } \\
\text { (5) } \\
\end{array}$} & \multicolumn{2}{|c|}{ D-in-D Estimates } \\
\hline & & \multicolumn{2}{|c|}{ Parametric } & \multirow[b]{2}{*}{ (4) } & & \multirow[b]{2}{*}{$(6)$} & \multirow[b]{2}{*}{$(7)$} \\
\hline & & $(2)$ & (3) & & & & \\
\hline \multicolumn{8}{|l|}{ 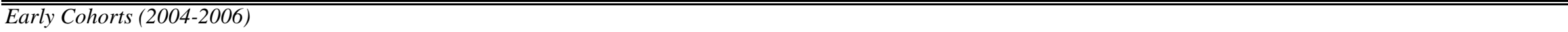 } \\
\hline \multirow[t]{2}{*}{ Covenant eligible } & 0.017 & -0.004 & -0.030 & 0.022 & -0.062 & 0.025 & 0.019 \\
\hline & $(0.039)$ & $(0.055)$ & $(0.051)$ & $(0.052)$ & {$[-0.168,0.044]$} & $(0.043)$ & $(0.042)$ \\
\hline \multicolumn{8}{|l|}{ Late Cohorts (2007-2010) } \\
\hline \multirow[t]{2}{*}{ Covenant eligible } & 0.007 & 0.047 & 0.045 & 0.047 & 0.058 & $0.077^{*}$ & $0.068 *$ \\
\hline & $(0.026)$ & $(0.040)$ & $(0.037)$ & $(0.037)$ & {$[-0.019,0.136]$} & $(0.041)$ & $(0.040)$ \\
\hline Data window & All data & $+/-150$ & $+/-75$ & $+/-75$ & All data & All data & All data \\
\hline Polynomial of running variable & quadratic & quadratic & linear & linear & -- & -- & -- \\
\hline Student-level covariates and year effects & yes & yes & no & yes & no & no & yes \\
\hline N(students, 2004-2006) & 6860 & 2118 & 1133 & 1133 & 716 & -- & -- \\
\hline Nonparametric bandwidth, 2004-2006 & -- & -- & -- & -- & 46.73 & -- & -- \\
\hline Outcome mean for control group, 2004-2006 & 0.83 & 0.78 & 0.76 & 0.76 & -- & -- & -- \\
\hline N(students, 2007-2010) & 8275 & 3330 & 1838 & 1838 & 1690 & -- & -- \\
\hline Nonparametric bandwidth, 2007-2010 & -- & -- & -- & -- & 68.52 & -- & -- \\
\hline Outcome mean for control group, 2007-2010 & 0.85 & 0.82 & 0.82 & 0.82 & -- & -- & -- \\
\hline N(students, 2003-2010) & -- & -- & -- & -- & -- & & \\
\hline Outcome mean for control group, 2003-2010 & -- & -- & -- & -- & -- & & \\
\hline
\end{tabular}

Notes: The analytic sample for the RD analyses includes the cohorts of 2004 to 2010. The analytic sample for the difference-in-differences specification includes the cohorts of 2003 to 2010 . The vector of studentlevel covariates includes measures of gender, race and ethnicity, high school GPA, SAT composite score, household size, and in the case of the difference-in-difference specification, real parental income (in 2010\$) and its square. For additional information on the difference-in-differences and RD approaches, please consult the text. In the RD models, we interact the function of the running variable with the indicator for

Covenant eligibility. Nonparametric RD estimates are calculated using a uniform (i.e., rectangular) kernel and data-driven bandwidth selection procedure described in Calonico, Cattaneo, and Titiunik (2014, 2015).

Robust 95-percent confidence intervals are shown in brackets. Robust standard errors appear in parentheses. ${ }^{* * *} \mathrm{p}<0.01,{ }^{* *} \mathrm{p}<0.05,{ }^{*} \mathrm{p}<0.10$. 


\section{Table 5. Effects of Covenant Eligibility on Credit Accumulation}

\begin{tabular}{|c|c|c|c|c|c|c|}
\hline \multirow[b]{3}{*}{ Outcome and Cohort Group } & \multicolumn{5}{|c|}{ RD Estimates } & \multirow{3}{*}{$\begin{array}{c}\text { Outcome Mean } \\
\text { Control Group } \\
\text { (6) }\end{array}$} \\
\hline & \multicolumn{4}{|c|}{ Parametric } & \multirow{2}{*}{$\begin{array}{c}\text { Nonparametric } \\
\text { (5) }\end{array}$} & \\
\hline & (1) & (2) & (3) & (4) & & \\
\hline \multicolumn{7}{|c|}{ ב. Outcome = Earned 30 credits 1 year after enrollment } \\
\hline Covenant eligible, early cohorts (2004-2006) & $\begin{array}{c}0.019 \\
(0.038)\end{array}$ & $\begin{array}{c}0.040 \\
(0.055)\end{array}$ & $\begin{array}{l}-0.012 \\
(0.054)\end{array}$ & $\begin{array}{c}0.020 \\
(0.051)\end{array}$ & $\begin{array}{c}-0.022 \\
{[-0.148,0.105]}\end{array}$ & 0.74 \\
\hline Covenant eligible, late cohorts (2007-2010) & $\begin{array}{c}0.058^{* * *} \\
(0.022)\end{array}$ & $\begin{array}{l}0.086^{* *} \\
(0.035)\end{array}$ & $\begin{array}{l}0.058^{*} \\
(0.030)\end{array}$ & $\begin{array}{c}0.065^{* *} \\
(0.029)\end{array}$ & $\begin{array}{c}0.075^{* *} \\
{[0.001,0.149]}\end{array}$ & 0.82 \\
\hline \multicolumn{7}{|c|}{ B. Outcome $=$ Earned 60 credits 2 years after enrollment } \\
\hline Covenant eligible, early cohorts (2004-2006) & $\begin{array}{c}0.044 \\
(0.041)\end{array}$ & $\begin{array}{c}0.017 \\
(0.056)\end{array}$ & $\begin{array}{l}-0.048 \\
(0.054)\end{array}$ & $\begin{array}{l}-0.010 \\
(0.053)\end{array}$ & $\begin{array}{c}-0.136^{*} \\
{[-0.272,0.001]}\end{array}$ & 0.72 \\
\hline Covenant eligible, late cohorts (2007-2010) & $\begin{array}{c}0.036 \\
(0.026)\end{array}$ & $\begin{array}{l}0.082^{* *} \\
(0.040)\end{array}$ & $\begin{array}{l}0.067^{*} \\
(0.039)\end{array}$ & $\begin{array}{l}0.065^{*} \\
(0.038)\end{array}$ & $\begin{array}{c}0.116^{* *} \\
{[0.019,0.214]}\end{array}$ & 0.77 \\
\hline \multicolumn{7}{|c|}{ C. Outcome = Earned 90 credits 3 years after enrollment } \\
\hline Covenant eligible, early cohorts (2004-2006) & $\begin{array}{l}-0.018 \\
(0.043)\end{array}$ & $\begin{array}{l}-0.094 \\
(0.060)\end{array}$ & $\begin{array}{c}-0.128 * * \\
(0.056)\end{array}$ & $\begin{array}{c}-0.107^{*} \\
(0.056)\end{array}$ & $\begin{array}{c}-0.208 * * * \\
{[-0.346,0.070]}\end{array}$ & 0.71 \\
\hline Covenant eligible, late cohorts (2007-2010) & $\begin{array}{l}0.054^{*} \\
(0.028)\end{array}$ & $\begin{array}{c}0.056 \\
(0.043)\end{array}$ & $\begin{array}{c}0.048 \\
(0.040)\end{array}$ & $\begin{array}{c}0.048 \\
(0.039)\end{array}$ & $\begin{array}{c}0.126^{* *} \\
{[0.009,0.243]}\end{array}$ & 0.75 \\
\hline$\overline{\text { Data window }}$ & All data & $+/-150$ & $+/-75$ & $+/-75$ & All data & $+/-75$ \\
\hline Polynomial of running variable & quadratic & quadratic & linear & linear & -- & -- \\
\hline Student-level covariates and year effects & yes & yes & no & yes & no & -- \\
\hline N(students, 2004-2006) & 6860 & 2118 & 1133 & 1133 & 664 to 713 & -- \\
\hline Nonparametric bandwidth range, 2004-2006 & -- & -- & -- & -- & 43 to 47 & -- \\
\hline N(students, 2007-2010) & 8275 & 3330 & 1838 & 1838 & 896 to 1494 & -- \\
\hline Nonparametric bandwidth range, 2007-2010 & -- & -- & -- & -- & 37 to 62 & -- \\
\hline
\end{tabular}

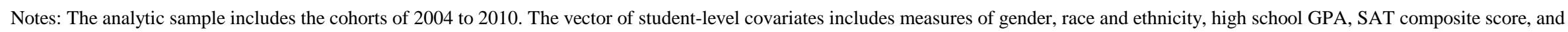
household size. In the RD models, we interact the function of the running variable with the indicator for Covenant eligibility. Nonparametric RD estimates are calculated using a uniform (i.e.,

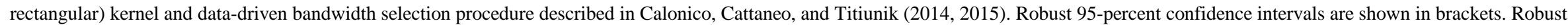
standard errors appear in parentheses. ${ }^{* * *} \mathrm{p}<0.01,{ }^{* *} \mathrm{p}<0.05,{ }^{*} \mathrm{p}<0.10$. 


\section{Table 6. Effects of Covenant Eligibility on Academic Performance}

\begin{tabular}{|c|c|c|c|c|c|c|}
\hline \multirow[b]{3}{*}{ Outcome and Cohort Group } & \multicolumn{5}{|c|}{ RD Estimates } & \multirow{3}{*}{$\begin{array}{c}\text { Outcome Mean } \\
\text { Control Group } \\
(6)\end{array}$} \\
\hline & \multicolumn{4}{|c|}{ Parametric } & \multirow{2}{*}{$\begin{array}{c}\text { Nonparametric } \\
\text { (5) }\end{array}$} & \\
\hline & (1) & (2) & (3) & (4) & & \\
\hline \multicolumn{7}{|c|}{ A. Outcome = Cumulative GPA 1 year after enrollment } \\
\hline Covenant eligible, early cohorts (2004-2006) & $\begin{array}{c}0.043 \\
(0.053)\end{array}$ & $\begin{array}{c}0.050 \\
(0.079)\end{array}$ & $\begin{array}{l}-0.053 \\
(0.078)\end{array}$ & $\begin{array}{c}0.044 \\
(0.073)\end{array}$ & $\begin{array}{c}-0.029 \\
{[-0.221,0.163]}\end{array}$ & 2.94 \\
\hline Covenant eligible, late cohorts (2007-2010) & $\begin{array}{c}0.064 \\
(0.039)\end{array}$ & $\begin{array}{c}0.063 \\
(0.058)\end{array}$ & $\begin{array}{c}0.067 \\
(0.058)\end{array}$ & $\begin{array}{c}0.068 \\
(0.053)\end{array}$ & $\begin{array}{c}0.080 \\
{[-0.072,0.232]}\end{array}$ & 3.04 \\
\hline \multicolumn{7}{|c|}{ B. Outcome = Cumulative GPA 2 years after enrollment } \\
\hline Covenant eligible, early cohorts (2004-2006) & $\begin{array}{c}0.056 \\
(0.052)\end{array}$ & $\begin{array}{c}0.065 \\
(0.077)\end{array}$ & $\begin{array}{l}-0.053 \\
(0.077)\end{array}$ & $\begin{array}{c}0.049 \\
(0.071)\end{array}$ & $\begin{array}{c}-0.086^{*} \\
{[-0.259,0.086]}\end{array}$ & 2.94 \\
\hline Covenant eligible, late cohorts (2007-2010) & $\begin{array}{l}0.084^{* *} \\
(0.036)\end{array}$ & $\begin{array}{c}0.088 \\
(0.054)\end{array}$ & $\begin{array}{c}0.079 \\
(0.054)\end{array}$ & $\begin{array}{c}0.081 \\
(0.050)\end{array}$ & $\begin{array}{c}0.127 * * \\
{[0.001,0.253]}\end{array}$ & 3.03 \\
\hline \multicolumn{7}{|c|}{ C. Outcome $=$ Cumulative GPA 3 years after enrollment } \\
\hline Covenant eligible, early cohorts (2004-2006) & $\begin{array}{c}0.086 \\
(0.064)\end{array}$ & $\begin{array}{c}0.106 \\
(0.077)\end{array}$ & $\begin{array}{l}-0.007 \\
(0.075)\end{array}$ & $\begin{array}{c}0.086 \\
(0.071)\end{array}$ & $\begin{array}{c}-0.013 \\
{[-0.168,0.140]}\end{array}$ & 2.96 \\
\hline Covenant eligible, late cohorts (2007-2010) & $\begin{array}{c}0.102^{* *} \\
(0.047)\end{array}$ & $\begin{array}{l}0.098^{*} \\
(0.055)\end{array}$ & $\begin{array}{c}0.088 \\
(0.055)\end{array}$ & $\begin{array}{l}0.091^{*} \\
(0.051)\end{array}$ & $\begin{array}{c}0.141^{*} \\
{[-0.006,0.288]}\end{array}$ & 3.05 \\
\hline$\overline{\text { Data window }}$ & All data & $+/-150$ & $+/-75$ & $+/-75$ & All data & $+/-75$ \\
\hline Polynomial of running variable & quadratic & quadratic & linear & linear & -- & -- \\
\hline Student-level covariates and year effects & yes & yes & no & yes & no & -- \\
\hline N(students, 2004-2006) & 6860 & 2118 & 1133 & 1133 & 698 to 988 & -- \\
\hline Nonparametric bandwidth range, 2004-2006 & -- & -- & -- & -- & 47 to 65 & -- \\
\hline N(students, 2007-2010) & 8275 & 3330 & 1838 & 1838 & 980 to 1257 & -- \\
\hline Nonparametric bandwidth range, 2007-2010 & -- & -- & -- & -- & 41 to 52 & -- \\
\hline
\end{tabular}

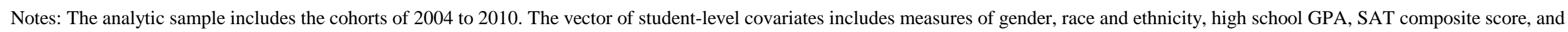
household size. In the RD models, we interact the function of the running variable with the indicator for Covenant eligibility. Nonparametric RD estimates are calculated using a uniform (i.e.,

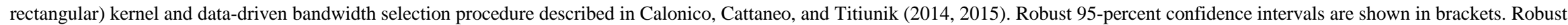
standard errors appear in parentheses. ${ }^{* * *} \mathrm{p}<0.01,{ }^{* *} \mathrm{p}<0.05,{ }^{*} \mathrm{p}<0.10$. 
Table 7. Heterogeneous Effects of Covenant Eligibility on Postsecondary Outcomes by Gender: Cohorts of 2007 to 2010

\begin{tabular}{|c|c|c|c|c|c|c|}
\hline \multirow[b]{3}{*}{ Subgroup and Outcome } & \multicolumn{5}{|c|}{ RD Estimates } & \multirow{3}{*}{$\begin{array}{c}\text { Outcome Mean } \\
\text { Control Group } \\
(6) \\
\end{array}$} \\
\hline & \multicolumn{4}{|c|}{ Parametric } & \multirow{2}{*}{$\begin{array}{c}\text { Nonparametric } \\
\text { (5) } \\
\end{array}$} & \\
\hline & $(1)$ & $(2)$ & (3) & (4) & & \\
\hline \multicolumn{7}{|l|}{ A. Outcome = Complete College in 4 Years } \\
\hline Covenant eligible, male & $\begin{array}{c}0.053 \\
(0.042)\end{array}$ & $\begin{array}{l}0.112 * \\
(0.067)\end{array}$ & $\begin{array}{l}0.108^{*} \\
(0.061)\end{array}$ & $\begin{array}{l}0.121 * \\
(0.062)\end{array}$ & $\begin{array}{c}0.145^{* *} \\
{[0.007,0.284]}\end{array}$ & 0.78 \\
\hline Covenant eligible, female & $\begin{array}{l}-0.020 \\
(0.033)\end{array}$ & $\begin{array}{c}0.010 \\
(0.050)\end{array}$ & $\begin{array}{c}0.001 \\
(0.046)\end{array}$ & $\begin{array}{c}0.009 \\
(0.046)\end{array}$ & $\begin{array}{c}-0.013 \\
{[-0.113,0.087]}\end{array}$ & 0.85 \\
\hline \multicolumn{7}{|c|}{ B. Outcome = Earned 30 Credits 1 Year After Enrollment } \\
\hline Covenant eligible, male & $\begin{array}{c}0.044 \\
(0.038)\end{array}$ & $\begin{array}{c}0.030 \\
(0.056)\end{array}$ & $\begin{array}{c}0.007 \\
(0.054)\end{array}$ & $\begin{array}{c}0.008 \\
(0.053)\end{array}$ & $\begin{array}{c}0.011 \\
{[-0.096,0.119]}\end{array}$ & 0.83 \\
\hline Covenant eligible, female & $\begin{array}{l}0.069 * * \\
(0.028)\end{array}$ & $\begin{array}{c}0.123^{* * *} \\
(0.045)\end{array}$ & $\begin{array}{l}0.083^{*} \\
(0.044)\end{array}$ & $\begin{array}{l}0.080 * \\
(0.042)\end{array}$ & $\begin{array}{c}0.116^{* *} \\
{[0.019,0.213]}\end{array}$ & 0.82 \\
\hline \multicolumn{7}{|c|}{ 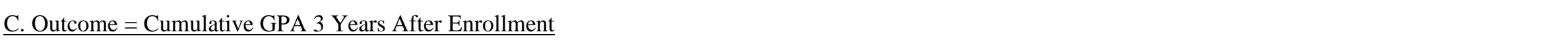 } \\
\hline Covenant eligible, male & $\begin{array}{l}0.135^{* *} \\
(0.065)\end{array}$ & $\begin{array}{c}0.120 \\
(0.094)\end{array}$ & $\begin{array}{c}0.116 \\
(0.089)\end{array}$ & $\begin{array}{c}0.118 \\
(0.085)\end{array}$ & $\begin{array}{c}0.160 * \\
{[-0.028,0.347]}\end{array}$ & 2.98 \\
\hline Covenant eligible, female & $\begin{array}{c}0.066 \\
(0.042)\end{array}$ & $\begin{array}{c}0.074 \\
(0.068)\end{array}$ & $\begin{array}{c}0.065 \\
(0.069)\end{array}$ & $\begin{array}{c}0.063 \\
(0.063)\end{array}$ & $\begin{array}{c}0.145^{*} \\
{[-0.023,0.312]}\end{array}$ & 3.10 \\
\hline Data window & All data & $+/-150$ & $+/-75$ & $+/-75$ & All data & $+/-75$ \\
\hline Polynomial of running variable & quadratic & quadratic & linear & linear & -- & -- \\
\hline Student-level covariates and year effects & yes & yes & no & yes & no & -- \\
\hline N(students, 2007-2010, male) & 3157 & 1284 & 720 & 720 & 507 & -- \\
\hline N(students, 2007-2010, female) & 5118 & 2046 & 1118 & 1118 & 918 & -- \\
\hline
\end{tabular}

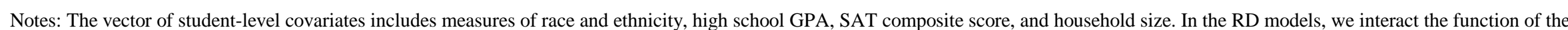
running variable with the indicator for Covenant eligibility. Nonparametric RD estimates are calculated using a uniform (i.e., rectangular) kernel and data-driven bandwidth selection procedure described in Calonico, Cattaneo, and Titiunik $(2014,2015)$. The sample sizes reported for the nonparametric estimates are the effective number of observations used by the estimator when the outcome is 4-year college graduation. Robust 95-percent confidence intervals are shown in brackets. Robust standard errors appear in parentheses. $* * * \mathrm{p}<0.01$, $* * \mathrm{p}<0.05$, $* \mathrm{p}<0.10$. 


\section{Appendix Figure A1. SAT Composite Score, Pre-Cohort of 2003}

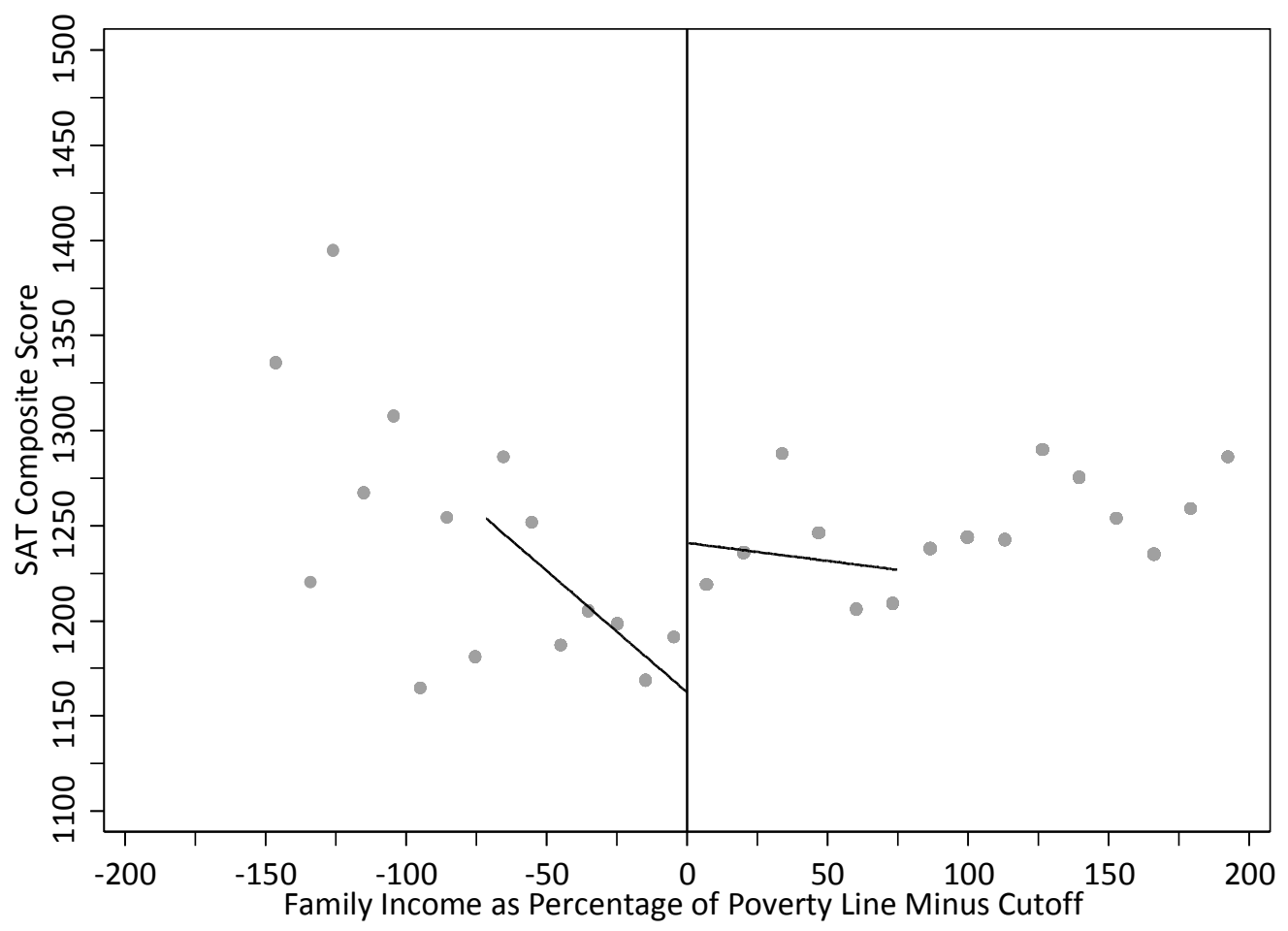

Notes: Solid lines represent local linear regressions within a data window of $+/-75$ of the cutoff using a rectangular kernel. 
Table A1. Test of Balance of Covariates at RD Cutoff

\begin{tabular}{|c|c|c|c|c|c|}
\hline \multirow[b]{2}{*}{ Outcome } & \multicolumn{4}{|c|}{ Parametric } & \multirow{2}{*}{$\begin{array}{c}\text { Nonparametric } \\
\text { (5) }\end{array}$} \\
\hline & (1) & $(2)$ & (3) & (4) & \\
\hline \multicolumn{6}{|l|}{ Early Cohorts, 2004-2006 } \\
\hline \multirow[t]{2}{*}{ SAT Composite Score } & $-40.244 * * *$ & $-43.218 * *$ & $-44.178 * * *$ & $-44.499 * * *$ & $-43.57 * *$ \\
\hline & $(12.241)$ & $(17.269)$ & $(16.160)$ & $(16.070)$ & {$[-78.246,-8.892]$} \\
\hline \multirow[t]{2}{*}{ High School GPA } & $-0.309 * * *$ & $-0.344 * * *$ & $-0.317^{* * *}$ & $-0.313^{* * *}$ & $-0.264^{* *}$ \\
\hline & $(0.079)$ & $(0.098)$ & $(0.091)$ & $(0.090)$ & {$[-0.481,-0.047]$} \\
\hline \multirow[t]{2}{*}{ Female } & 0.014 & 0.054 & 0.037 & 0.036 & 0.046 \\
\hline & $(0.044)$ & $(0.063)$ & $(0.058)$ & $(0.058)$ & {$[-0.115,0.207]$} \\
\hline \multirow[t]{2}{*}{ White } & $-0.170 * * *$ & -0.016 & -0.062 & -0.061 & -0.063 \\
\hline & $(0.045)$ & $(0.064)$ & $(0.059)$ & $(0.059)$ & {$[-0.191,0.064]$} \\
\hline N(students) & 6860 & 2118 & 1133 & 1133 & 623 to 988 \\
\hline \multicolumn{6}{|l|}{ Pre-Cohort of 2003} \\
\hline \multirow[t]{2}{*}{ SAT Composite Score } & $-63.491 *$ & -58.166 & $-78.541 * *$ & $-78.541 * *$ & -43.06 \\
\hline & (33.023) & $(38.422)$ & $(36.311)$ & $(36.311)$ & {$[-122.435,36.320]$} \\
\hline \multirow[t]{2}{*}{ High School GPA } & -0.192 & -0.126 & -0.237 & -0.237 & -0.222 \\
\hline & $(0.141)$ & $(0.155)$ & $(0.144)$ & $(0.144)$ & {$[-0.589,0.145]$} \\
\hline \multirow[t]{2}{*}{ Female } & $0.180^{* *}$ & 0.087 & 0.054 & 0.054 & 0.046 \\
\hline & $(0.090)$ & $(0.111)$ & $(0.104)$ & $(0.104)$ & {$[-0.232,0.323]$} \\
\hline \multirow[t]{2}{*}{ White } & $-0.332^{* * *}$ & -0.136 & -0.128 & -0.128 & $-0.339 * *$ \\
\hline & $(0.091)$ & $(0.116)$ & $(0.110)$ & $(0.110)$ & {$[-0.609,0.068]$} \\
\hline $\mathrm{N}$ (students) & 2165 & 600 & 319 & 319 & 148 to 235 \\
\hline \multicolumn{6}{|l|}{ Late Cohorts, 2007-2010 } \\
\hline \multirow[t]{2}{*}{ SAT Composite Score } & -11.474 & -1.956 & -1.608 & -3.182 & 15.995 \\
\hline & $(8.557)$ & (12.829) & $(11.962)$ & $(11.846)$ & {$[-15.59,47.58]$} \\
\hline \multirow[t]{2}{*}{ High School GPA } & $-0.121^{* *}$ & -0.045 & -0.005 & -0.022 & 0.054 \\
\hline & $(0.049)$ & $(0.069)$ & $(0.067)$ & $(0.066)$ & {$[-0.107,0.215]$} \\
\hline \multirow[t]{2}{*}{ Female } & -0.014 & 0.006 & 0.012 & 0.012 & -0.035 \\
\hline & $(0.032)$ & $(0.048)$ & $(0.045)$ & $(0.045)$ & {$[-0.140,0.070]$} \\
\hline \multirow[t]{2}{*}{ White } & $-0.079 *$ & -0.048 & -0.026 & -0.029 & -0.000 \\
\hline & $(0.042)$ & $(0.049)$ & $(0.046)$ & $(0.046)$ & {$[-0.122,0.121]$} \\
\hline N(students) & 8275 & 3330 & 1838 & 1838 & 947 to 1174 \\
\hline Data window & All data & $+/-150$ & $+/-75$ & $+/-75$ & All data \\
\hline Polynomial of running variable & quadratic & quadratic & linear & linear & -- \\
\hline Year effects & yes & yes & no & yes & no \\
\hline
\end{tabular}

Notes: In the RD models, we interact the function of the running variable with the indicator for Covenant eligibility. Nonparametric RD estimates are calculated using a uniform (i.e., rectangular) kernel and data-driven bandwidth selection procedure described in Calonico, Cattaneo, and Titiunik (2014, 2015). Robust 95-percent confidence intervals are shown in brackets. Robust standard errors appear in parentheses. *** $\mathrm{p}<0.01, * * \mathrm{p}<0.05, * \mathrm{p}<0.10$. 


\section{Appendix Table A2. Effects of Covenant Eligibility on Postsecondary Persistence}

\begin{tabular}{|c|c|c|c|c|c|c|}
\hline \multirow[b]{3}{*}{ Outcome and Cohort Group } & \multicolumn{5}{|c|}{ RD Estimates } & \multirow{3}{*}{$\begin{array}{c}\text { Outcome Mear } \\
\text { Control Group } \\
(6)\end{array}$} \\
\hline & \multicolumn{4}{|c|}{ Parametric } & \multirow{2}{*}{$\begin{array}{c}\text { Nonparametric } \\
\text { (5) } \\
\end{array}$} & \\
\hline & $(1)$ & $(2)$ & $(3)$ & $(4)$ & & \\
\hline \multicolumn{7}{|l|}{ A. Outcome = Persist to 2nd Year of College } \\
\hline \multirow[t]{2}{*}{ Covenant eligible, early cohorts (2004-2006) } & 0.016 & 0.005 & 0.005 & 0.005 & 0.019 & 0.97 \\
\hline & $(0.013)$ & $(0.022)$ & $(0.019)$ & $(0.019)$ & {$[-0.021,0.058]$} & \\
\hline \multirow[t]{2}{*}{ Covenant eligible, late cohorts (2007-2010) } & -0.017 & -0.011 & -0.013 & -0.015 & -0.011 & 0.97 \\
\hline & $(0.012)$ & $(0.018)$ & $(0.017)$ & $(0.017)$ & {$[-0.057,0.034]$} & \\
\hline \multicolumn{7}{|l|}{ B. Outcome $=$ Persist to 3rd Year of College } \\
\hline \multirow[t]{2}{*}{ Covenant eligible, early cohorts (2004-2006) } & 0.030 & 0.020 & 0.003 & 0.003 & 0.005 & 0.94 \\
\hline & $(0.020)$ & $(0.030)$ & $(0.027)$ & $(0.027)$ & {$[-0.059,0.070]$} & \\
\hline \multirow[t]{2}{*}{ Covenant eligible, late cohorts (2007-2010) } & -0.024 & -0.026 & -0.029 & -0.022 & -0.016 & 0.95 \\
\hline & $(0.016)$ & $(0.024)$ & $(0.022)$ & $(0.027)$ & {$[-0.074,0.043]$} & \\
\hline \multicolumn{7}{|l|}{ C. Outcome $=$ Persist to 4 th Year of College } \\
\hline \multirow[t]{2}{*}{ Covenant eligible, early cohorts (2004-2006) } & 0.033 & 0.027 & 0.019 & 0.015 & 0.035 & 0.90 \\
\hline & $(0.024)$ & $(0.034)$ & $(0.032)$ & $(0.032)$ & {$[-0.034,0.099]$} & \\
\hline \multirow[t]{2}{*}{ Covenant eligible, late cohorts (2007-2010) } & -0.003 & -0.014 & -0.021 & -0.023 & -0.024 & 0.92 \\
\hline & $(0.018)$ & $(0.027)$ & $(0.025)$ & $(0.025)$ & {$[-0.083,0.034]$} & \\
\hline Data window & All data & $+/-150$ & $+/-75$ & $+/-75$ & All data & $+/-75$ \\
\hline Polynomial of running variable & quadratic & quadratic & linear & linear & -- & -- \\
\hline Student-level covariates and year effects & yes & yes & no & yes & no & -- \\
\hline N(students, 2004-2006) & 6860 & 2118 & 1133 & 1133 & 704 to 993 & -- \\
\hline Nonparametric bandwidth range, 2004-2006 & -- & -- & -- & -- & 52 to 65 & -- \\
\hline N(students, 2007-2010) & 8275 & 3330 & 1838 & 1838 & 964 to 1283 & -- \\
\hline Nonparametric bandwidth range, 2007-2010 & -- & -- & -- & -- & 41 to 53 & -- \\
\hline
\end{tabular}

Notes: The analytic sample includes the cohorts of 2004 to 2010. Persistence is measured according to whether a student is observed attempting any credits X years after initial enrollment. The vector of student-level covariates includes measures of gender, race and ethnicity, high school GPA, SAT composite score, and household size. In the RD models, we interact the function of the running variable with the indicator for Covenant eligibility. Nonparametric RD estimates are calculated using a uniform (i.e., rectangular) kernel and data-driven bandwidth selection procedure

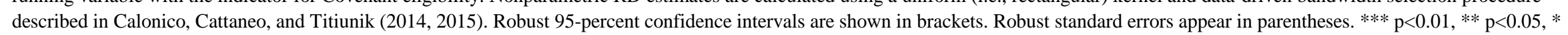
$\mathrm{p}<0.10$. 


\section{Appendix Table A3. Effects of Covenant Eligibility on Major Choice}

\begin{tabular}{|c|c|c|c|c|c|}
\hline \multirow[b]{3}{*}{ Cohort Group } & \multicolumn{5}{|c|}{$\begin{array}{c}\text { Outcome = STEM Major, Final } \\
\text { RD Estimates }\end{array}$} \\
\hline & \multicolumn{4}{|c|}{ Parametric } & \multirow{2}{*}{$\begin{array}{c}\text { Nonparametric } \\
(5) \\
\end{array}$} \\
\hline & $(1)$ & $(2)$ & $(3)$ & $(4)$ & \\
\hline \multicolumn{6}{|l|}{ Early Cohorts (2004-2006) } \\
\hline Covenant eligible & $\begin{array}{l}-0.076^{*} \\
(0.042)\end{array}$ & $\begin{array}{c}-0.135^{* *} \\
(0.063)\end{array}$ & $\begin{array}{c}-0.105^{*} \\
(0.058)\end{array}$ & $\begin{array}{l}-0.084 \\
(0.058)\end{array}$ & $\begin{array}{c}-0.168^{* *} \\
{[-0.311,-0.024]}\end{array}$ \\
\hline \multicolumn{6}{|l|}{ Late Cohorts (2007-2010) } \\
\hline Covenant eligible & $\begin{array}{c}0.034 \\
(0.033)\end{array}$ & $\begin{array}{c}0.067 \\
(0.049)\end{array}$ & $\begin{array}{c}0.093 * * \\
(0.046)\end{array}$ & $\begin{array}{l}0.083 * \\
(0.045)\end{array}$ & $\begin{array}{c}0.069 \\
{[-0.023,0.161]}\end{array}$ \\
\hline Data window & All data & $+/-150$ & $+/-75$ & $+/-75$ & All data \\
\hline Polynomial of running variable & quadratic & quadratic & linear & linear & -- \\
\hline Student-level covariates and year effects & yes & yes & no & yes & no \\
\hline N(students, 2004-2006) & 6443 & 1970 & 1054 & 1054 & 644 \\
\hline Nonparametric bandwidth, 2004-2006 & -- & -- & -- & -- & 45.67 \\
\hline Outcome mean for control group, 2004-2006 & 0.34 & 0.35 & 0.35 & 0.35 & -- \\
\hline N(students, 2007-2010) & 7793 & 3115 & 1722 & 1722 & 1531 \\
\hline Nonparametric bandwidth, 2007-2010 & -- & -- & -- & -- & 66.51 \\
\hline Outcome mean for control group, 2007-2010 & 0.37 & 0.37 & 0.37 & 0.37 & -- \\
\hline
\end{tabular}

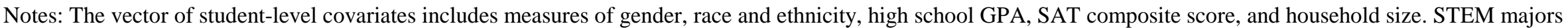
include the following majors (CIP codes): Agriculture, Agriculture Operations, and Related Sciences (01); Natural Resources and Conservation (03); Architecture and Related Services (04); Computer and Information Sciences and Support Services (11); Engineering (14); Biological and Biomedical Sciences (26); Mathematics and Statistics (27); Physical Sciences (40); Psychology (42); and Health Professions and Related Clinical Sciences (51). In the RD models, we interact the function of the running variable with the indicator for Covenant eligibility. Nonparametric RD estimates are calculated using a uniform (i.e., rectangular) kernel and data-driven

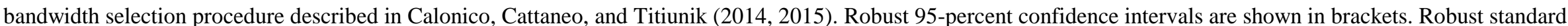
errors appear in parentheses. ${ }^{* * *} \mathrm{p}<0.01,{ }^{* *} \mathrm{p}<0.05$, $^{*} \mathrm{p}<0.10$. 
Appendix Table A4. Heterogeneous Effects of Covenant Eligibility on College Completion by Gender: Cohorts of 2004 to 2006

\begin{tabular}{|c|c|c|c|c|c|}
\hline \multirow[b]{3}{*}{ Subgroup } & \multicolumn{5}{|c|}{$\begin{array}{c}\text { Outcome }=\text { Complete college in } 4 \text { years } \\
\text { RD Estimates }\end{array}$} \\
\hline & \multicolumn{4}{|c|}{ Parametric } & \multirow{2}{*}{$\begin{array}{c}\text { Nonparametric } \\
\text { (5) } \\
\end{array}$} \\
\hline & $(1)$ & $(2)$ & $(3)$ & $(4)$ & \\
\hline \multicolumn{6}{|l|}{ Early Cohorts (2004-2006) } \\
\hline \multirow[t]{2}{*}{ Covenant eligible, male } & -0.041 & -0.105 & -0.068 & -0.038 & -0.137 \\
\hline & $(0.070)$ & $(0.095)$ & $(0.088)$ & $(0.090)$ & {$[-0.367,0.093]$} \\
\hline \multirow[t]{2}{*}{ Covenant eligible, female } & 0.049 & 0.056 & -0.011 & -0.010 & -0.040 \\
\hline & $(0.046)$ & $(0.067)$ & $(0.062)$ & $(0.063)$ & {$[-0.181,0.102]$} \\
\hline Data window & All data & $+/-150$ & $+/-75$ & $+/-75$ & All data \\
\hline Polynomial of running variable & quadratic & quadratic & linear & linear & -- \\
\hline Student-level covariates and year effects & yes & yes & no & yes & no \\
\hline N(students, 2004-2006, male) & 2570 & 765 & 421 & 421 & 254 \\
\hline Outcome mean for control group, males & 0.80 & 0.74 & 0.74 & 0.74 & -- \\
\hline N(students, 2004-2006, female) & 4290 & 1353 & 712 & 712 & 511 \\
\hline Outcome mean for control group, females & 0.85 & 0.80 & 0.78 & 0.78 & -- \\
\hline
\end{tabular}

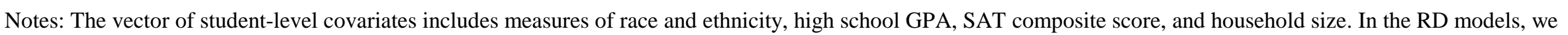
interact the function of the running variable with the indicator for Covenant eligibility. Nonparametric RD estimates are calculated using a uniform (i.e., rectangular) kernel and data-driven bandwidth selection procedure described in Calonico, Cattaneo, and Titiunik (2014, 2015). Robust 95-percent confidence intervals are shown in brackets. Robust standard errors appear in parentheses. ${ }^{* * *} \mathrm{p}<0.01,{ }^{* *} \mathrm{p}<0.05,{ }^{*} \mathrm{p}<0.10$. 